\title{
Annotation of the Asian Citrus Psyllid Genome Reveals a Reduced Innate Immune System
}

\author{
Alex P. Arp ${ }^{1}$, Wayne B. Hunter ${ }^{2}$ and Kirsten S. Pelz-Stelinski ${ }^{1 *}$ \\ ${ }^{1}$ Citrus Research and Education Center, Department of Entomology and Nematology, University of Florida, Fort Pierce, FL, \\ USA, ${ }^{2}$ U.S. Horticultural Research Lab, Agricultural Research Service, United State Department of Agriculture, Fort Pierce, \\ FL, USA
}

Citrus production worldwide is currently facing significant losses due to citrus greening disease, also known as Huanglongbing. The citrus greening bacteria, Candidatus Liberibacter asiaticus (CLas), is a persistent propagative pathogen transmitted by the Asian citrus psyllid, Diaphorina citri Kuwayama (Hemiptera: Liviidae). Hemipterans characterized to date lack a number of insect immune genes, including those associated with the Imd pathway targeting Gram-negative bacteria. The $D$. citri draft genome was used to characterize the immune defense genes present in $D$. citri. Predicted mRNAs identified by screening the published $D$. citri annotated draft genome were manually searched using a custom database of immune genes from previously annotated insect genomes. Toll and JAK/STAT pathways, general defense genes Dual oxidase, Nitric oxide

Edited by:

Arash Zibaee,

University of Gilan, Iran

Reviewed by:

Nicolas Durand

University of Orléans, France

Jose Eduardo Serrão,

Universidade Federal de Viçosa, Brazil

Muthugounder S. Shivakumar,

Periyar University, India

*Correspondence: Kirsten S. Pelz-Stelinski

pelzstelinski@ufl.edu

Specialty section:

This article was submitted to Invertebrate Physiology, a section of the journal

Frontiers in Physiology

Received: 02 August 2016 Accepted: 09 November 2016 Published: 29 November 2016

Citation:

Arp AP, Hunter WB and

Pelz-Stelinski KS (2016) Annotation of the Asian Citrus Psyllid Genome

Reveals a Reduced Innate Immune

System. Front. Physiol. 7:570

doi: 10.3389/fphys.2016.00570 synthase, prophenoloxidase, and cellular immune defense genes were present in $D$. citri. In contrast, $D$. citri lacked genes for the Imd pathway, most antimicrobial peptides, 1,3- $\beta$ glucan recognition proteins (GNBPs), and complete peptidoglycan recognition proteins. These data suggest that $D$. citri has a reduced immune capability similar to that observed in $A$. pisum, $P$. humanus, and $R$. prolixus. The absence of immune system genes from the $D$. citri genome may facilitate CLas infections, and is possibly compensated for by their relationship with their microbial endosymbionts.

Keywords: Diaphorina citri, immune, genes, Imd, liberibacter, antimicrobial peptide, virus

\section{INTRODUCTION}

Insects transmit a wide range of animal and plant pathogens. The majority of vector-borne pathogen research has focused on viral zoonotic and plant pathogens, with commensurate attention given to understanding the physiological factors that promote interactions between the pathogen and vector (Fereres and Moreno, 2009; Sim et al., 2014). Insects lack the adaptive immune system found in chordates, and instead rely exclusively on an innate immune system to regulate interactions with invading microorganisms. The insect innate immune system consists of humoral and cellular defense responses activated by pattern recognition receptors (PRRs), which detect and bind to conserved microbial surface structures, called pathogen-associated molecular patterns (PAMPs), (Pili-Floury et al., 2004; Dziarski and Gupta, 2006; Wang et al., 2011).

Holometabolous insects, including Drosophila, Anopheles spp. (Diptera), and Tribolium castaneum, (Coleoptera) have served as important models for genomic and functional investigations of insect innate immunity (Christophides et al., 2002; Hoffmann and Reichhart, 2002; Roth et al., 2010). The high level of similarity in immune function shared among these 
insects, other non-insect arthropods, and vertebrates, is suggestive of a highly conserved innate immune system (Kang et al., 1998; McTaggart et al., 2009; Smith and Pal, 2014). In contrast, three hemimetabolous insects, the pea aphid, Acyrthosiphon pisum (Family: Aphididae), kissing bug, Rhodnius prolixus, (Family: Reduviidae) and human louse, Pediculus humanus, (Family: Pediculidae) possess comparatively reduced innate immune systems that lack genes for recognition and killing of Gram-negative bacteria (Gerardo et al., 2010; Kim et al., 2011; Mesquita et al., 2015).

Like A. pisum, the hemimetabolous Asian citrus psyllid, Diaphorina citri Kuwayama, (Hemiptera: Liviidae) is also host to a number of endosymbionts and the plant bacterial pathogen associated with citrus greening disease, Candidatus Liberibacter asiaticus (CLas) (Aubert, 1987; Thao et al., 2000; Halbert and Manjunath, 2004). Currently, citrus greening disease, or Huanglongbing, threatens worldwide citrus production (Hall et al., 2013). Psyllids transmit CLas, a Gram-negative alphaproteobacteria, beginning a few days to a week after acquisition and for the lifetime of the vector (Pelz-Stelinski et al., 2010; Ammar et al., 2011). D. citri harbors CLas in a persistentpropagative manner, suggesting that CLas has developed mechanisms to avoid psyllid cellular and humoral immune defenses.

Circulative, persistent pathogens must traverse immunological and physical barriers in the midgut and salivary glands before they can be transmitted to plants during subsequent feeding. Within the midgut, the invading pathogen must pass through the peritrophic matrix (if present), survive exposure to antimicrobial peptides (AMPs) and reactive oxygen species (ROS), compete with resident gut bacteria, and pass though the gut epithelium (Ha et al., 2005; Charroux and Royet, 2010; Kuraishi et al., 2011). Once in the hemocoel, pathogens must avoid phagocytosis, encapsulation, melanization, and effectors produced by the fat body (Ratcliffe and Gagen, 1976; Lavine and Strand, 2002; Hillyer et al., 2003). To overcome these immune barriers, insect pathogens have evolved mechanisms to avoid the insect defenses, such as not expressing PAMPs, degrading effectors, inhibiting immune signaling pathways, or killing hemocytes (Apidianakis et al., 2005; Vallet-Gely et al., 2008). Understanding vector immune responses may lead to novel management strategies to reduce insect-transmitted pathogens (Reese et al., 2014). This is evident in the recently successful manipulation of mosquito immune responses through the introduction of Wolbachia, resulting in the upregulation of immunity genes and inhibition of dengue virus replication (Moreira et al., 2009; Pan et al., 2012).

Mechanisms that facilitate CLas evasion of psyllid cellular and humoral innate immune defenses are unknown. We used the unpublished D. citri genome (Hunter et al., 2014) to annotate immune system genes and determine phylogenetic relationships with homologous sequences from other insects. Immune genes were automatically annotated with the NCBI Eukaryotic Automated Annotation Pipeline and manually annotated using a tblastx search of the predicted $D$. citri transcripts against a database of insect immune genes. Here, we illustrate that D. citri may resemble their close Sternorrhynchan relative, $A$. pisum, which have a reduced immune response toward Gramnegative bacteria compared to well-characterized homopterous insect models (Figure 1). The shared feeding habits and reliance of $A$. pisum and D. citri on Gram-negative obligate nutritional symbionts suggest that these Hemipterans may have a shared history of adaptations promoting close relationships with this group of microorganisms.

\section{MATERIALS AND METHODS}

\section{Insects}

Diaphorina citri were collected from a citrus grove in Ft. Pierce, FL (GPS coordinates $27.4389^{\circ} \mathrm{N}, 80.3356^{\circ} \mathrm{W}$ ) and reared at the USDA, ARS, U.S. Horticultural Research Laboratory, Ft. Pierce, FL. D. citri were caged for feeding on Murraya paniculata for 2 years, then Citrus macrophylla for the following 2 years. Psyllids and plants were maintained under natural day length cycles. Adult $D$. citri were collected within 1 month of emergences, submerged in liquid nitrogen, and held at $-80^{\circ} \mathrm{C}$ until nucleic acid preparation.

\section{Cloning and Purification of Insect Nucleic Acids}

RNA purification and sequencing followed identical protocols as described in Reese et al. (2014). Total RNA was extracted using the Qiagen RNeasy Mini Kit, per manufacturer recommended protocol. mRNA purification utilized a poly-T oligo-attached magnetic beads, Conversion into cDNA done using the mRNA sequencing preparation kit from Illumina (part number 1004898). Sequencing of the cDNA was performed on an Illumina GAIIx sequencing system.

\section{Genome}

The D. citri genome is available on National Center for Biotechnology Information (NCBI) under Genome Sequencing Project-RefSeq: Accession: PRJNA29447 ID: 29447 (http:// www.ncbi.nlm.nih.gov/bioproject/PRJNA29447) and the I5K arthropod genome project (https://i5k.nal.usda.gov/Diaphorina_ citri).

\section{Gene Identification and Annotation}

The comprehensive list of $D$. citri genes related to immune defenses was curated by screening for immune genes within the $D$. citri draft genome version 1.1 previously annotated by the NCBI automated refseq eukaryote genome annotation pipeline (Hunter et al., 2014). Also included were published sequences produced by recent deep sequencing surveys of D. citri (Hunter et al., 2014; Vyas et al., 2015). Immune related genes of interest were selected based on previous surveys of arthropod immune pathways and immunological defenses (Gerardo et al., 2010; González-Santoyo and Córdoba-Aguilar, 2011; Buchon et al., 2014; Smith and Pal, 2014). In addition to screening published sequences, a manual search for $D$. citri immune related genes was performed to search for genes not identified in previous annotations and to check the validity of the automated pipeline annotations. The manual search was implemented by first locally blasting $D$. citri predicted transcripts 


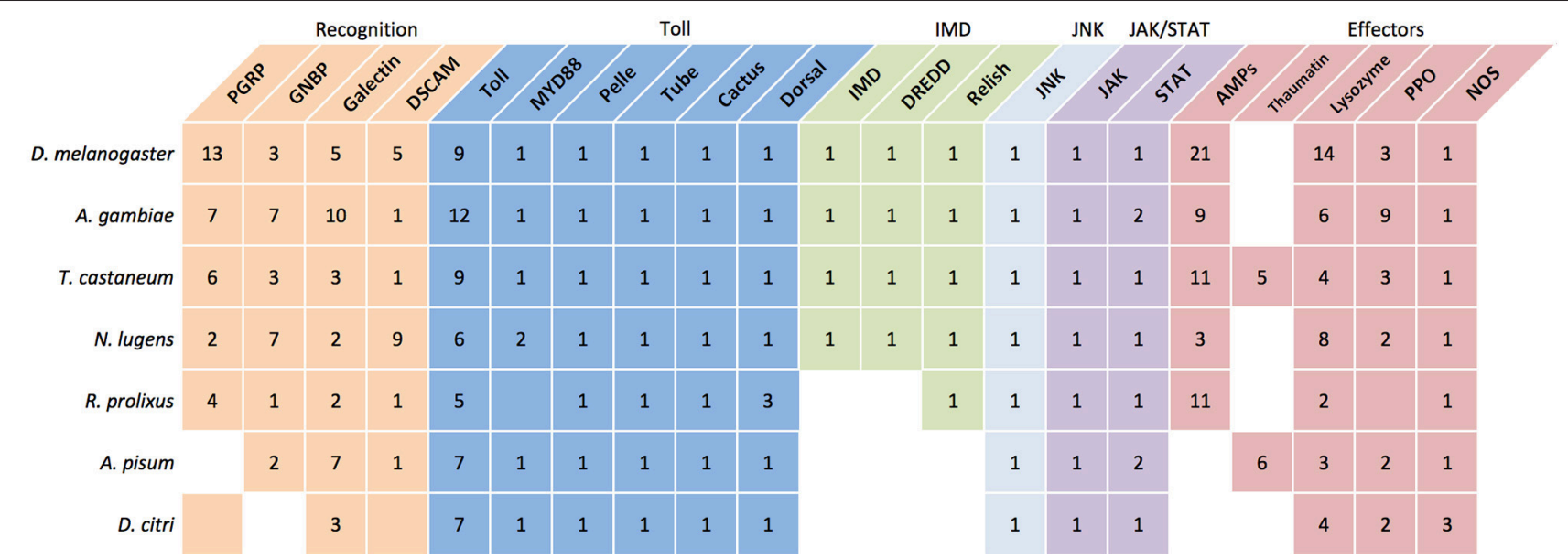

FIGURE 1 | A comparison of select immune associates genes in select model insects and $D$. citri suggests $A$. pisum and $D$. citri have similar immune pathway characteristics. The number in each box represents the reported copy number of each gene. Empty boxes represent genes that have not been identified. Boxes that are colored but lacking a number are assumed to be present but the specific number is unknown or the potential gene function is putative. (Christophides et al., 2002; Sackton et al., 2007; Gerardo et al., 2010; Bao et al., 2013; Mesquita et al., 2015).

against a locally curated list of immune related genes from Drosophila melanogaster (flybase.org), A. pisum, Apis mellifera, Aedes aegypti (vectorbase.org), Bombyx mori, and Nilaparvata lugens with the tblastx search algorithm. Geneious software (http://www.geneious.com, version 7.1.5) was used to conduct BLAST searches (Kearse et al., 2012) with results limited to hits with $e$-values of $<1 \mathrm{e}^{-5}$. The identities of predicted transcripts with positive matches in the initial tblastx search were validated performing a BLAST search of all insect protein sequences in the NCBI nr database using blastp. Immune genes identified with the manual search were submitted to NCBI and sequences mislabeled by the automated annotation pipeline were updated.

\section{Phylogenetic Tree}

Phylogenetic analysis of Hdd11, glutathione s-transferases, and lysozymes, were created with Geneious tree builder (http://www.geneious.com, version 7.1.5). The trees were created by global alignment with free end gaps, identity cost matrix, Jukes-Cantor genetic distance model, and neighbor-joining tree building method. Sequences used are listed in supplemental tables: Hdd11 (Table S3), lysozymes (Table S4), and glutathione s-transferases (Table S5).

\section{RESULTS AND DISCUSSION}

\section{Recognition Proteins}

\section{Peptidoglycan Recognition Protein}

Peptidoglycan recognition proteins (PGRPs) bind to the peptidoglycan in the bacterial cell and activate cellular signaling pathways, induce the melanization cascade, have amidase activity, or act an opsonization factors (Dziarski and Gupta, 2006). The structure of peptidoglycan is conserved between classes of bacteria with Gram-positive having Llysine type peptidoglycan and Gram-negative bacteria and Gram-positive bacilli are made of Dap-type peptidoglycan in their respective cell walls (Schleifer and Kandler, 1972). The conserved nature of peptidoglycan aids in the efficiency of the insect immune response and prevents adaptations that would allow bacteria to avoid recognition. PGRPs are also highly conserved, being first identified in insects and subsequently identified in humans, mice, and other vertebrates (Kang et al., 1998).

There are two classes of PGRPs in insects: short cytostolic PGRP-Ss and long membrane-bound PGRP-Ls, both containing a 166 bp PGRP domain (IPR002502) located at the C-terminal region (Werner et al., 2000; Dziarski and Gupta, 2005). The number of PGRPs found in insects is diverse; for example, D. melanogaster has seven short and 10 long PGRPs, while A. gambiae has three short and four long PGRPs (Werner et al., 2000; Christophides et al., 2002). The diversity of PGRPs is associated with a variety of downstream responses. PGRP-SA, SD, and SC are activated by Lys-type peptidoglycan and subsequently cleave Spaetzle, inducing the Toll pathway (Michel et al., 2001; Gottar et al., 2002; Bischoff et al., 2004). PGRP-LC and SCla activate phagocytosis of bacteria (Rämet et al., 2002; Garver et al., 2006). PGRP-LC in association with PGRP-LE recognize Dap-type peptidoglycan and activate the Imd pathway (Choe et al., 2002; Gottar et al., 2002; Werner et al., 2003; Takehana et al., 2004). PGRPs were not evident in the $D$. citri genome, though one gene coding for a lysM peptidoglycan-binding domain-containing protein was identified, though lacking the PGRP domain (Table 1). Despite being highly conserved among other holometabolous insects, they are absent from the genomes of at least two hemimetabolous insects, the pea aphid, A. pisum, and human louse, Pediculus spp., challenging the assumption that all insects possess relatively similar innate immune signaling pathways (Gerardo et al., 2010; Kim et al., 2011). The phylogenetic proximity of D. citri to $A$. pisum, both of the suborder Sternorrhyncha, implies that the absence of PGRP may be a shared trait among insects in this 


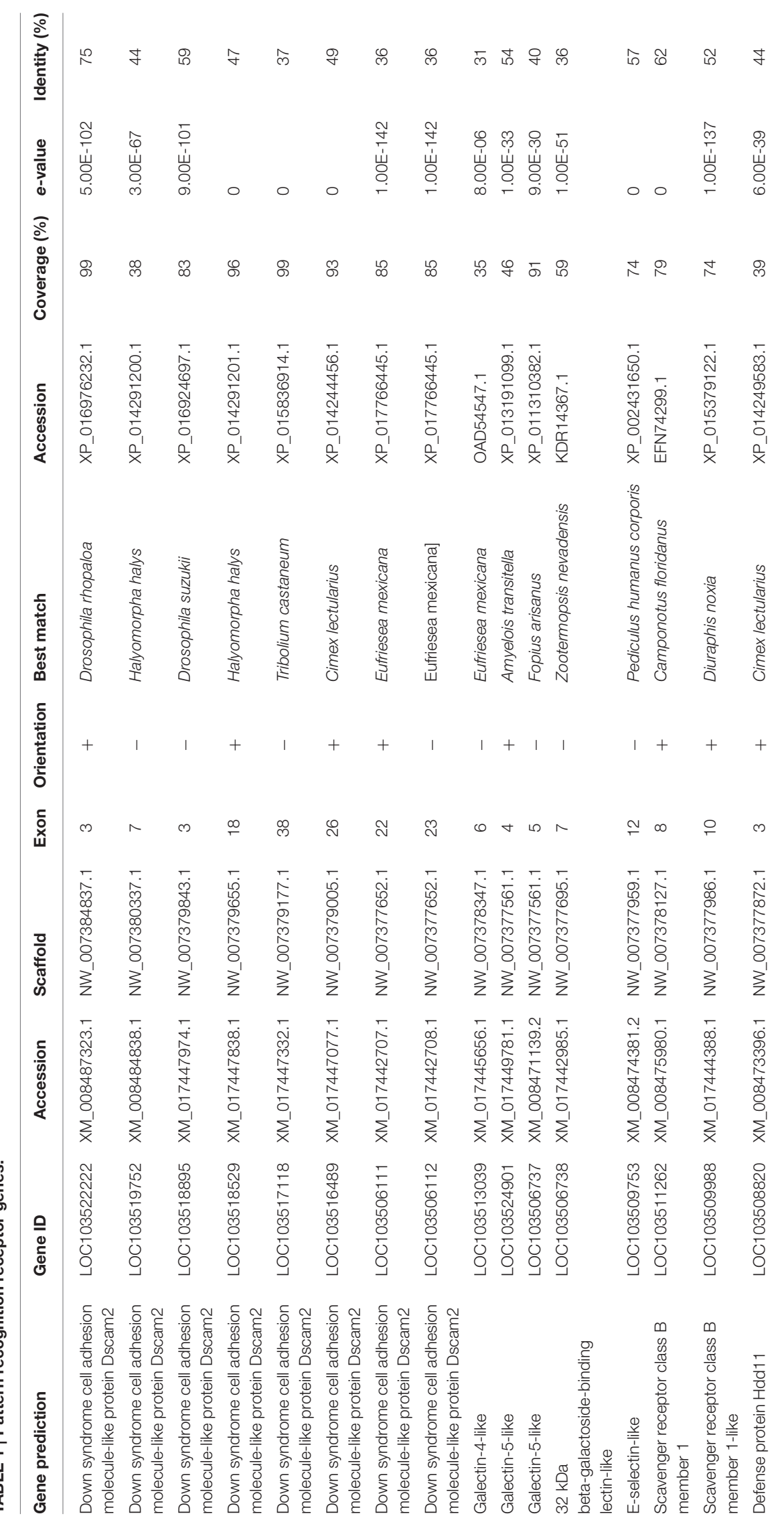


suborder. Though absent in these species, an investigation into the innate immune systems of the Hemipterans $N$. lugens and $R$. prolixus identified PGRPs, insinuating that the loss of PGRP is not a trait of all Hemiptera but specific to Sternorrhyncha (Bao et al., 2013; Mesquita et al., 2015).

\section{Gram-Negative Binding Proteins}

$\beta$-1,3-glucan recognition proteins ( $\beta$ GRPS), or Gram-negative binding proteins (GNBPs), are hemolymph-soluble PRRs that bind to the surface of Gram-positive bacteria or fungi. Binding results in the activation of serine proteases that initiate the Toll pathway, resulting in the production of antimicrobial peptides, or activating the prophenoloxidase melanization cascade (Roh et al., 2009; Wang et al., 2011). The structure of GNBP1 and GNBP-3 consists of a C-terminal GNBP homology domain followed by a N-terminal $\beta$-1,3-glucan binding domain, while GNBP-2 lacks the C-terminal GNBP domain. GNBP1 forms a complex with PGRP-SA, with both required to cleave Spaetzle and initiate an immune response via the Toll pathway (Gobert, 2003; Pili-Floury et al., 2004). GNBP-2 does not have glucanase activity, but binds to laminarin and lipoteichoic acid, and is associated with activating phenoloxidase (Jiang et al., 2004). GNBP-3, like GNBP -1, activates the Toll pathway in association with surface receptor binding (Gottar et al., 2006).

Gram-negative binding proteins and $\beta$-1,3-glucan recognition proteins were not found in $D$. citri, but are present in Hemipterans A. pisum, N. lugens, and R. prolixus (Ursic-Bedoya and Lowenberger, 2007; Gerardo et al., 2010; Bao et al., 2013). The presence of GNBP-1 in pea aphids is particularly interesting given that GNBP-1 in Drosophila does not function in the absence of PGRP-SA, which A. pisum lacks (Gobert, 2003; Gerardo et al., 2010). The absence of GNBPs in D. citri is unique, and may explain the high mortality of $D$. citri observed in response to entomopathogenic fungi in field and laboratory studies (Aubert, 1987; Avery et al., 2009, 2011).

\section{DSCAM}

Down syndrome cell adhesion molecule (DSCAM) is a pathogen recognition and embryonic development protein with a diversity of potential spliceforms (Schmucker and Chen, 2009). Alternative splicing of DSCAM pre-RNA results in a potential for 38,016 isoforms that may enhance the arthropod-pathogen recognition response (Watson et al., 2005). Alternate splicing is suspected to be influenced by pathogen activation of the Toll and Imd pathways (Dong et al., 2006, 2012a). There are two forms of DSCAM: a membrane-bound form in hemocytes, and a hemolymph soluble form.

Eight regions of repeated Ig domains similar to the gene structure of DSCAM were identified in D. citri (Table 1). Due to the highly variable nature of these regions, complete annotation of this gene was not completed, but it can be assumed that $D$. citri does possess at least one complete gene coding for DSCAM. The lack of PGRP and GNBP found in $D$. citri could indicate an increased need for DSCAMinitiated humoral immune recognition and defense against microorganisms. The absence of PGRPs and GNBPs necessary for Toll and Imd pathway activation in D. citri suggests that these immune pathways do not exclusively control the alternative splicing of DSCAM. It is also possible that DSCAM in D. citri is exclusively associated with neuronal function and development rather than immune function.

\section{Other Pattern Recognition Receptors}

Galectins are a family of soluble, carbohydrate-binding proteins found in all metazoan organisms. They serve a number of functions, including cell adhesion, proliferation, migration, apoptosis, inflammation, and immunity (Hughes, 2001; Rabinovich et al., 2002). Insect galectins may act as PRRs, effectors, and aid hemocytes through agglutination and opsonization of bacteria (Baum et al., 2014).

Another diverse family of immune related binding proteins are the C-type lectins. C-type lectins are denoted as calciumdependent carbohydrate-binding proteins, though they may or may not have calcium-binding or carbohydrate-binding regions, and thus the name is a misnomer. The structural motif of $\mathrm{C}$ type lectins consists of a mannose-binding domain and act as PRRs (Zelensky and Gready, 2005; Tian et al., 2009). C-type lectins can be membrane-bound or extracellular. The function of C-type lectins is as diverse as those seen in galectins and has been implicated in prophenoloxidase activation, phagocytosis, and hemocyte proliferation (Yu and Kanost, 2003; Ling et al., 2008; Tian et al., 2009).

D. citri has a wide variety of potential recognition proteins, including C-type lectins and galectins (Table 1). Further investigations are needed to determine the functions of these proteins and their role in the $D$. citri immune response.

Animals have numerous leucine-rich repeat containing proteins (LRRs) that serve a variety of functions in cells, including acting as PRRs. In the Lepidopteran, Manduca sexta, a LRR, Leureptin, was found to bind to lipopolysaccharide and interact with hemocytes, potentially acting as an opsonization factor (Zhu et al., 2010). In A. gambiae, two LRRs, APL1, and LRIM1, aid in TEP1 binding to Plasmodium in a complement system (Fraiture et al., 2009). The D. citri genome annotation identified 46 LRRs with unknown functions (Table S1). Further transcriptional analysis of $D$. citri following immune challenge will elucidate if any of these proteins participate in immune functions.

Proteins containing a reeler domain are involved in the nodulation response, binding hemocytes to lipopolysaccharides, lipoteichoic acid, and beta-1,3 glucans, and can be involved in the phenoloxidase cascade (Gandhe et al., 2007; Bao et al., 2011). $D$. citri has one predicted sequence containing a reeler domain, defense protein Hdd11 (Table 1). A phylogenetic comparison of Hdd11 to effector molecules from other insects showed that this gene has sequence similarity with N. lugens Reeler (KC355218.1) and B. mori Immune response proteins (NM_001098349.1, NM_001257010.1) which contain a reeler domain (Figure 2).

\section{Immune Signaling Pathways Toll}

The Toll pathway is associated with the insect innate immune response to Gram-positive bacteria and fungi (Aggarwal and 


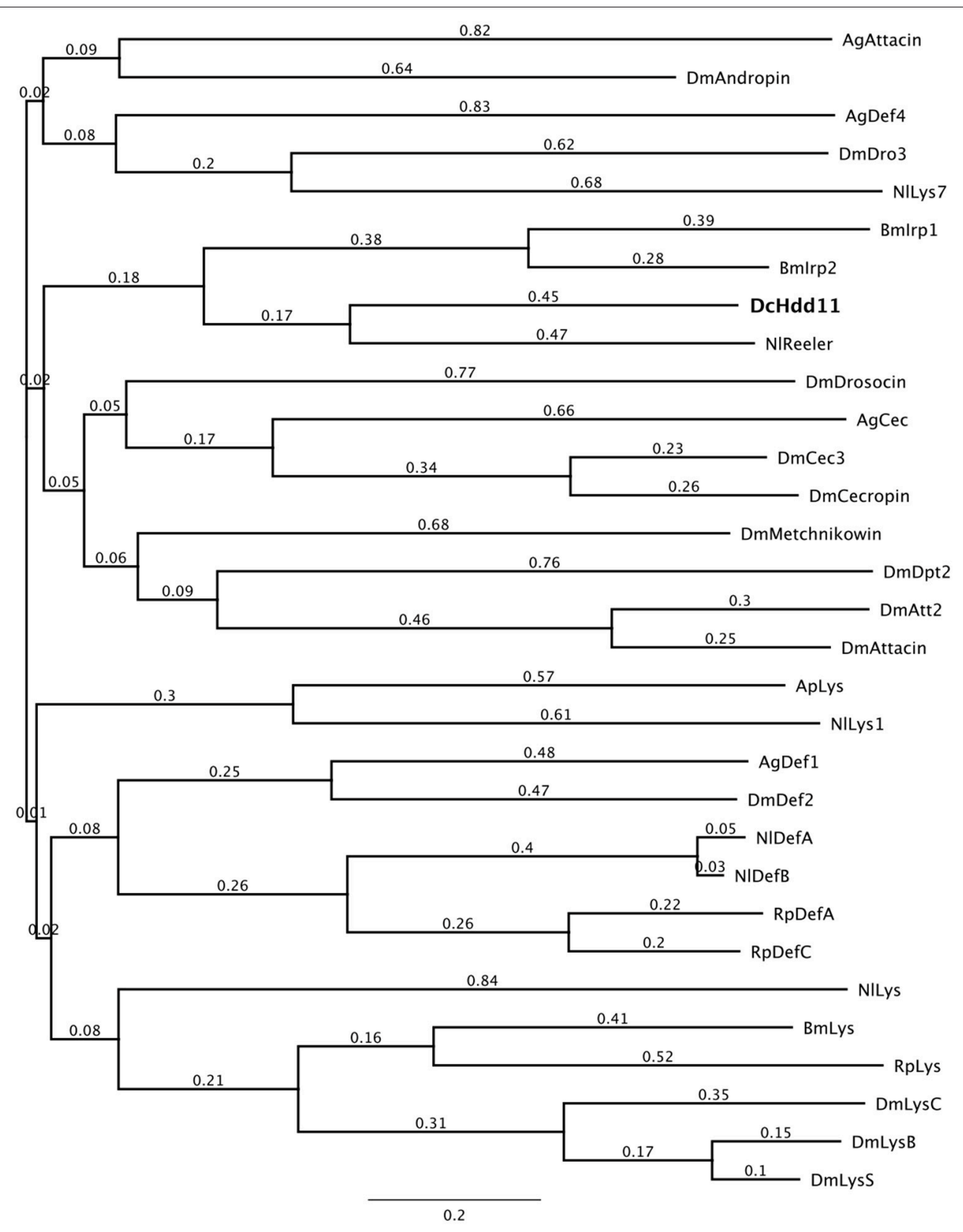

FIGURE 2 | A phylogenetic comparison of insect effectors with D. citri predicted defensive protein Hdd11 (XM_008473396.1). The phylogenetic tree was constructed using the Geneious (Version 7.1, Kearse et al., 2012) Tree Builder. Branch labels signify substitutions per site. Sequences used are listed in Table S3. Dm, Drosophila melanogaster; Ag, Anopheles gambiae, Ap, Acyrthosiphon pisum; NI, Nilaparvata lugens; Bm, Bombyx mori; Dc, Diaphorina citri, Rp, Rhodnius prolixus.

Silverman, 2008; Hetru and Hoffmann, 2009). Additionally, the Toll pathway in insects is involved in dorsal-ventral cellular patterning in embryonic development (Hashimoto et al., 1988). Microbial activation of the Toll pathway in Drosophila has been observed to activate the production of antimicrobial peptides and induce the propagation and differentiation of hemocytes (Valanne et al., 2011; Buchon et al., 2014).

The Toll receptor is membrane-bound, consisting of extracellular regions of leucine-rich repeats (LRRs) flanked by cysteine-rich domains, with the exception of Toll9, which has only one cysteine-rich domain before the transmembrane domain (Tauszig et al., 2000; Imler and Hoffmann, 2001). The intracellular portion of the Toll receptor is a Toll/IL-1R (TIR) domain that connects with the downstream signaling proteins (Imler and Hoffmann, 2001).

Toll activation occurs when Spaetzle binds to the Toll receptor (Weber et al., 2003). Spaetzle is activated by proteolysis of its 
prodomain following microbial detection (Arnot et al., 2010). Proteolysis requires a Spaetzle-processing enzyme (SPE), which is activated by one of three signal cascades elicited in response to different classes of microorganisms. Two of these cascades are activated by Gram-positive-specific serine protease (Grass), and a third by the serine protease, Persephone (Ligoxygakis et al., 2002a; Gottar et al., 2006). Following Spaetzle binding to the Toll receptor, the intracellular Toll TIR domain binds directly to the heteromeric death domain containing proteins MyD88, Tube, and Pelle by the TIR domain on MyD88 (Sun et al., 2002; Moncrieffe et al., 2008). Signal transduction through these scaffold proteins leads to the phosphorylation and degradation of Cactus, which is bound to the NF-kappaB-like transcription factors Dif or Dorsal (Kidd, 1992). Once separated from Cactus, Dif and Dorsal initiate transcription of antimicrobial peptide genes or other immune responses (Ip et al., 1993; Gross et al., 1996; Rutschmann et al., 2000).

Genes for six Toll receptors, one Spaetzle, and the intracellular signaling components MyD88, Pelle, Tube, Cactus, and Dorsal were identified in D. citri (Table 2). The role of Toll in the D. citri immune response is unclear, given that PGRP and GNBP genes associated with microbial recognition were not detected. Fungal detection receptors Persephone and Necrotic were also absent, which may explain the high mortality of $D$. citri in response to fungal pathogens (Aubert, 1987; Avery et al., 2009, 2011). The Toll pathway in D. citri is similar to that of A. pisum, which has a complete Toll pathway but lacks PGRPs. A. pisum has two genes coding for GNBPs that may function in fungal recognition. A. pisum also produce Thaumatins, a group of antifungal peptides, which were not detected in D. citri (Gerardo et al., 2010).

\section{Imd and JNK}

Insect recognition and systemic responses to Gram-negative bacteria are exclusively associated with the immune deficiency (Imd) pathway (Kleino and Silverman, 2014). The PRRs associated with the Imd pathway are the transmembrane PGRP-LC receptor and extracellular PGRP-LE, which work synergistically (Takehana et al., 2004). The intracellular signaling cascade is a complex of connector protein Imd that bind to FADD through their death domains and caspace-8 homolog DREDD. DREDD cleaves the N-terminal portion of NFkappa-B transcription factor Relish and also Imd. Relish induces production of antimicrobial peptides (Hedengren et al., 1999). Cleaved and ubiquinated, Imd recruits TAK1 and TAB2 dimer, which subsequently phosphorylates Kenny/IKKb (Geuking et al., 2009). The Kenny/IKKb complex will either phosphorylate Relish, leading to nuclear translocation, or MKK7/hemipterous, which will lead to phosphorylation of Basket and c-Jun N-terminal kinase (JNK) (Geuking et al., 2009; Cao et al., 2015). JNK is a mitogen-activated protein kinase (MAPK) pathway involved in apoptosis, wound healing, and phagocytosis (Rämet et al., 2002; Mizutani et al., 2003).

The Imd pathway was mostly absent in D. citri, although TBK1 and the downstream JNK pathway was identified

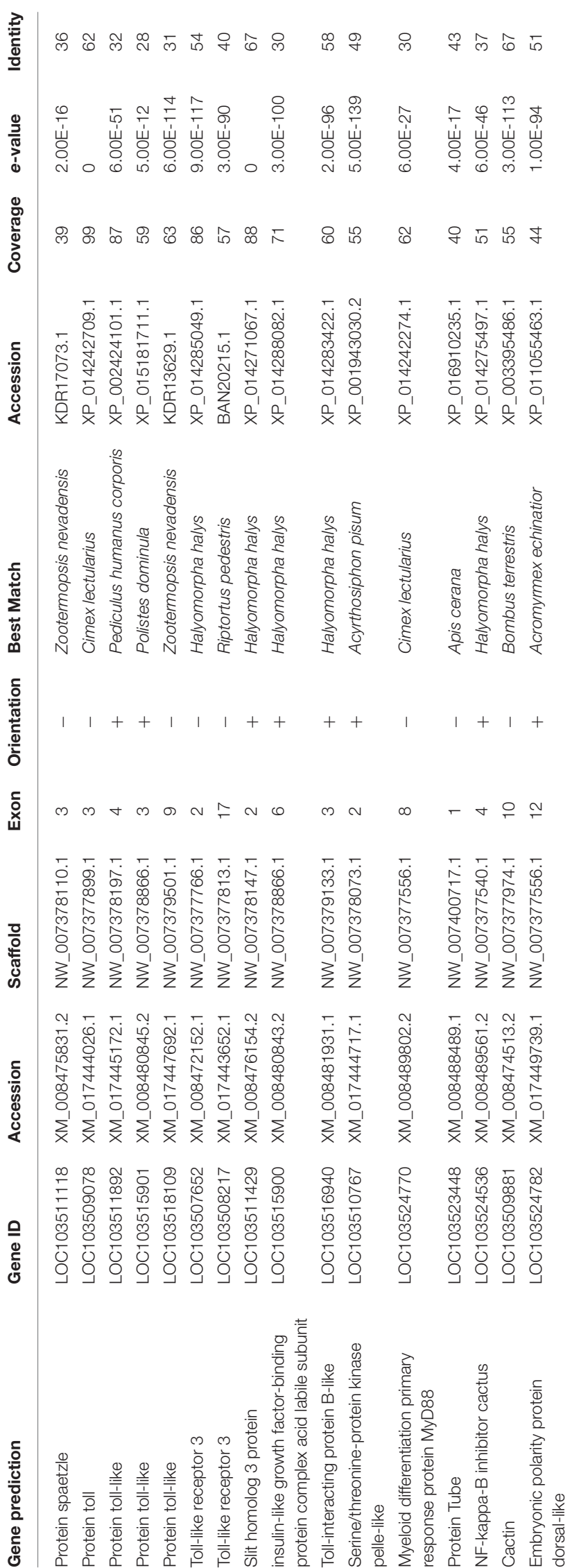


(Table 3), suggesting that alternative activation of JNK may occur. R. prolixus, A. pisum, and P. humanus also lack a portion of, or the entire Imd pathway (Gerardo et al., 2010; Kim et al., 2011; Mesquita et al., 2015). Absence of the Imd pathway is possibly associated with the evolution of the relationships all Sternorrhyncha share with bacterial endosymbionts (Altincicek et al., 2008). Sternorrhynchan endosymbionts are primarily Gram-negative bacteria, though some harbor yeast-like symbionts, thus absence of the Imd pathway may facilitate colonization of the insect host, an adaptation that allowed these insects to feed on nutritionally-poor plant phloem or xylem. Facultative symbionts may benefit insects by providing antimicrobial or parasitoid defense, expanding host range, or expanding heat tolerance (Montllor et al., 2002; Oliver et al., 2003; Scarborough et al., 2005; McLean et al., 2011; Ye et al., 2013). The benefits of the facultative symbionts are suspected to be strong drivers of speciation in this group (Tsuchida et al., 2004, 2011; Cordaux et al., 2011).

\section{JAK/STAT}

The Janus kinase/signal transducer activator of transcription (JAK/STAT) pathway functions in embryonic development, and participates in humoral and cellular immune responses to bacteria, fungi, parasitoids, and viruses (Sorrentino et al., 2004; Dostert et al., 2005; Cronin et al., 2009; Souza-Neto et al., 2009; Dong et al., 2012b; Kingsolver et al., 2013). Unlike the Toll and Imd pathways, which are activated in response to PRR binding to PAMPs, the JAK/STAT pathway is activated by cytokines (Harrison et al., 1998; Agaisse and Perrimon, 2004). Extracellular cytokine binding to a pair of transmembrane cytokine receptors activates a JAK proteins on the intracellular region, which phosphorylate Domeless (Brown et al., 2001). STAT92E (STAT) then binds to Domeless and becomes phosphorylated (Hou et al., 2002). Phosphorylated STATs dimerize and pass into the nucleus, where they act as transcription factors (Yan et al., 1996). The primary components of the JAK/STAT pathway were identified in D. citri (Table 5).

JAK/STAT activation in response to stress or immune challenge increases the expression of Tot and thioestercontaining proteins (Teps), in Drosophila (Lagueux et al., 2000; Agaisse et al., 2003). Tot proteins do not have direct antibacterial properties, but are associated with the general stress response and may function as transcription factors for cellular protection or repair (Ekengren and Hultmark, 2001). Neither Tep nor Tot were identified in D. citri (Table 4).

JAK/STAT is also involved in the differentiation and proliferation of hemocytes (Minakhina et al., 2011). Proliferation of hemocytes is activated by STAT92E, promoting the expression of Raf MAPK, while Raf has been seen to interact with Hopscotch independent of STAT92E, leading to the proliferation of hemocytes (Luo et al., 2002). One Raf-like protein gene was identified in D. citri (Table 5). Further investigation is needed to expand current understanding of the JAK/STAT pathway in $D$. citri immune responses.

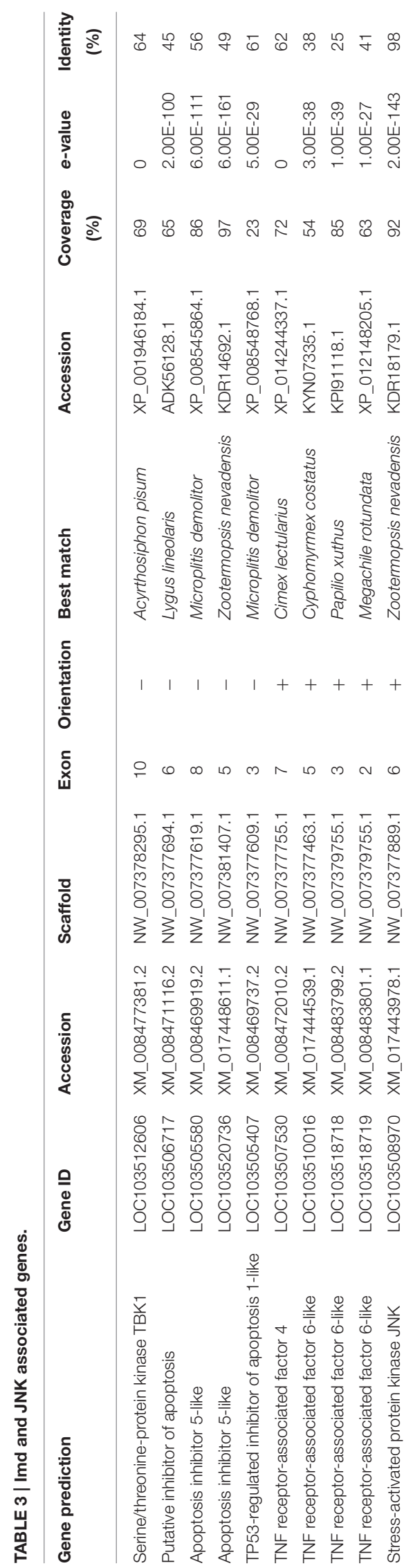




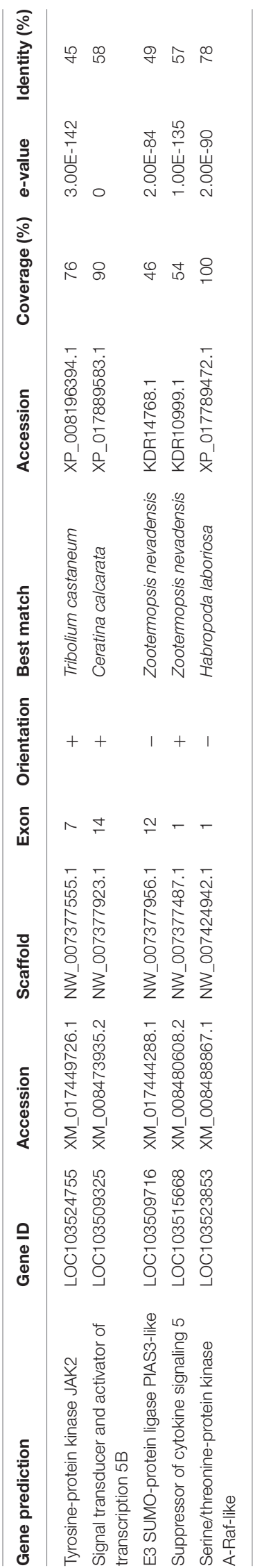

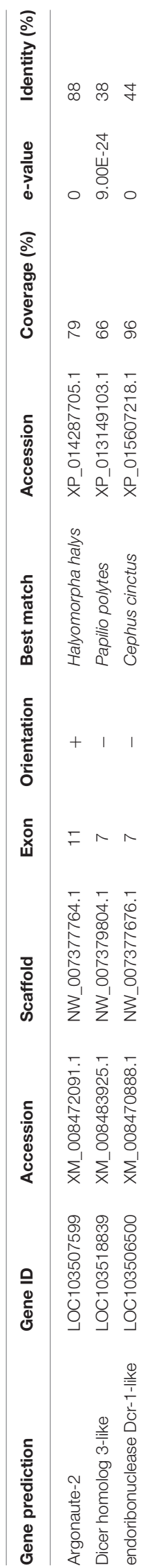

\section{Immune Response \\ RNAi}

Toll, Imd, and JAK/STAT pathways are involved in viral recognition and response; however, RNA interference (RNAi) is the primary antiviral defense system used by insects. Viral double-stranded RNAs (dsRNA) are detected and used as templates for recognition and detection of the same viral RNA. Dicer-2, in conjunction with R2D2, detects viral RNA and cleaves it into short 21-22 bp segments (Elbashir et al., 2001; Liu et al., 2003). The short dsRNA segment is bound to a RNA-induced silencing complex (RISC) of Argonaut and C3P0, and the passenger strand is degraded (Hammond et al., 2001). The RISC complex uses the remaining guide strand to bind to complementary viral mRNAs, cleave them, and inhibit viral replication. Silencing insect genes using RNAi is a promising new tool for D. citri management (El-Shesheny et al., 2013; Killiny et al., 2014). The primary components of the RNAi system, Argonaut, Dicer, and SID-1, were identified in D. citri (Table 5). Although C3P0 was not identified in D. citri, Argonaut-2 can function as an endonuclease without the presence of other associated RNAi proteins (Rand et al., 2004). In contrast, the absence of R2D2 is surprising, given that it is required for proper loading of double-stranded RNA into Dicer (Liu et al., 2006).

\section{Melanization and Clotting}

Melanization of wound sites and invading microorganisms is a primary terminal component of the arthropod immune system and is often used to quantify immune response (Cerenius et al., 2008; Tang, 2009). Melanization is activated by both the Toll and Imd pathways (Takehana et al., 2002; Park et al., 2007). Activation of prophenoloxidase (PPO) by serine proteases produces defensive cytotoxic quinones, and aids in phagocytosis and blood clotting (Theopold et al., 2004; Liu et al., 2007; Zhao et al., 2007). Due to the potential for self-harm by quinones, PPO activation is a highly regulated system that produces a localized and rapid response (Ligoxygakis et al., 2002b; Michel et al., 2005; Nappi et al., 2005). D. citri has the components of the PPO pathway (Table 7). Melanization occurs rapidly in extracted hemolymph and following cuticular puncture (personal observation). In contrast, A. pisum does not exhibit a strong melanization response to cuticle punctures (Altincicek et al., 2008). Further investigations will determine the role of PPO genes in response to pathogen infection.

Melanization is a major component of wound healing in insects, but it is not necessary for clotting. A group of proteins called hemolectins, or hemocytins, and Fondue, participate in clotting and inhibition of bacterial invasion (Lesch et al., 2007). Hemocytins, including von Willebrand factors and discoidins, have domains homologous to vertebrate clotting factors (Kotani et al., 1995). Knockdown of hemolectins reduces clotting ability but does not affect survival of bacterial infections, even in cases of oral exposure to the pathogen (Lesch et al., 2007; Chang et al., 2012). Hemocyins also contribute to nodulation after pathogen exposure, aiding in cellular immune responses (Arai et al., 2013). We identified three hemocytins, although the Drosophila clotting protein Fondue was not identified (Table 6). 


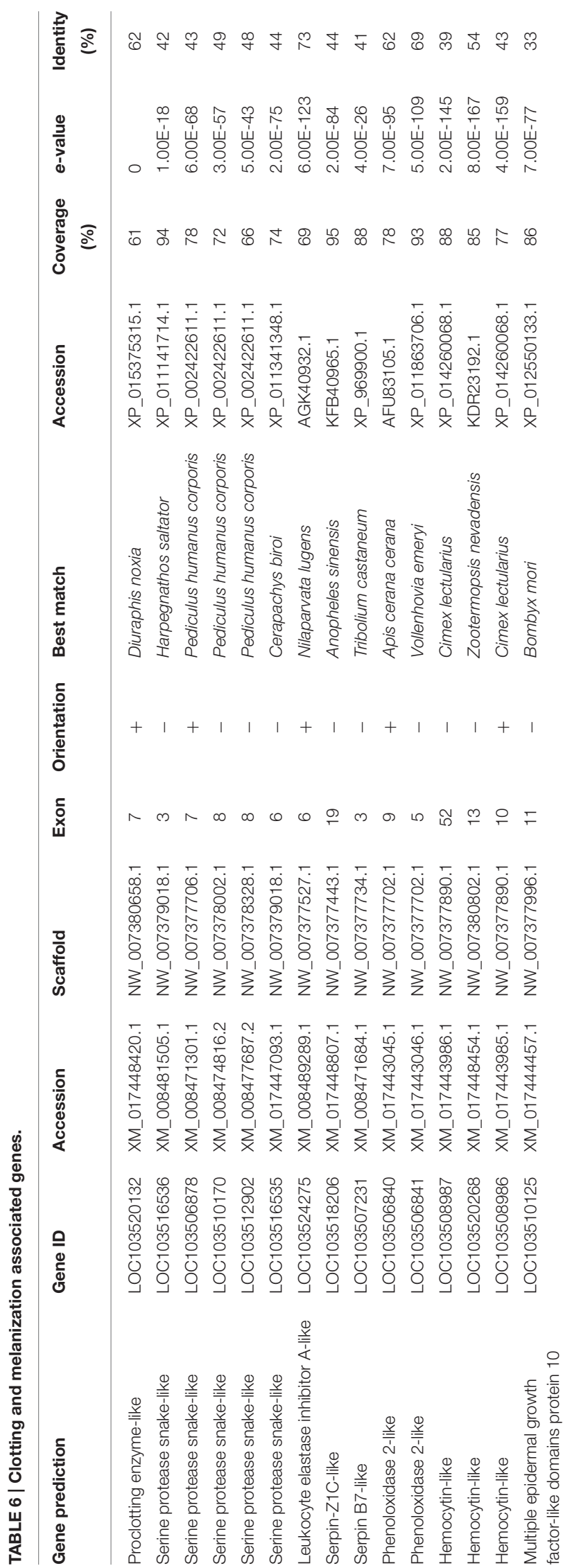

\section{Antimicrobial Peptides}

Antimicrobial peptides (AMPs) are produced by all organisms, including bacteria, as a component of the innate immune system (Hancock and Diamond, 2000). These peptides are generally short, $<100$ residues long, yet they are diverse and have rapid rates of evolution. Evidence of this is apparent on the Antimicrobial Peptide Database, which contains over 2100 unique sequences [http://aps.unmc.edu/AP/main.php, (Wang et al., 2009)]. In insects, AMPs are often produced continuously to provide basal immunity against invading pathogens and to manage endosymbiont populations. They are also induced in response to the presence of microorganisms (Login et al., 2011). Most insects produce a wide variety of AMPs, often simultaneously, to ensure that the invading microorganism is eliminated and possibly to reduce the development of AMP resistance (Dobson et al., 2013). AMPs generally function by disrupting the cell membrane of bacterial cells due to their cationic and amphipathic structure (Brown and Hancock, 2006). Antifungal peptides, including thaumatins, such as those produced by aphids, were also absent (Gerardo et al., 2010). The lack of a diverse pool of antimicrobial peptides in $D$. citri as compared with other Hemipterans, Drosophila, and holometabolous insects, suggests that their absence in $D$. citri is the result of gene loss rather than a basal state.

Four lysozymes genes were present in D. citri (Table 7). Lysozymes are a specific group of cell wall-disrupting antimicrobial proteins that defend against bacteria and fungus found in both vertebrates and invertebrates. There are two types of lysozymes found in insects, i- and c-type, both of which have been observed to be involved in digestion and immune defenses, indicating that function is species specific or related to tissue level expression rather than associated with type (Mohamed et al., 2016). A comparison of lysozyme genes identified in $D$. citri with classified lysozymes in other insects indicates that two are likely c-type and one is i-type (Figure S1). The fourth lysozyme does not align with other lysozyme sequences and may be misannotated.

\section{Nitric Oxygen Synthase}

Invertebrate nitric oxides, produced by nitric oxide synthase (NOS), participate in neuron metabolism and immune response. Nitric oxides are highly diffusible and can cause reactions at very low concentrations. High concentrations of nitric oxide are cytotoxic to both microorganisms and the organism producing the NO (Kang et al., 1998; Colasanti et al., 2002). Insect NOS is upregulated in response to Gram-negative bacteria, fungi, and plasmodium parasites (Luckhart et al., 1998; Foley and O'Farrell, 2003). Two sequences were identified as a partial NOS in $D$. citri (Table 7). A. aegypti, A. mellifera, and T. castaneum all possess a single NOS gene, which suggests that the partial NOS sequences observed in D. citri may be portions of the complete gene (McTaggart et al., 2009).

\section{Chitinase}

Insects produce a variety classes of chitinases involved in molting, digestion, and cell proliferation following immune challenge (Arakane and Muthukrishnan, 2009). Anopheles gambiae have 


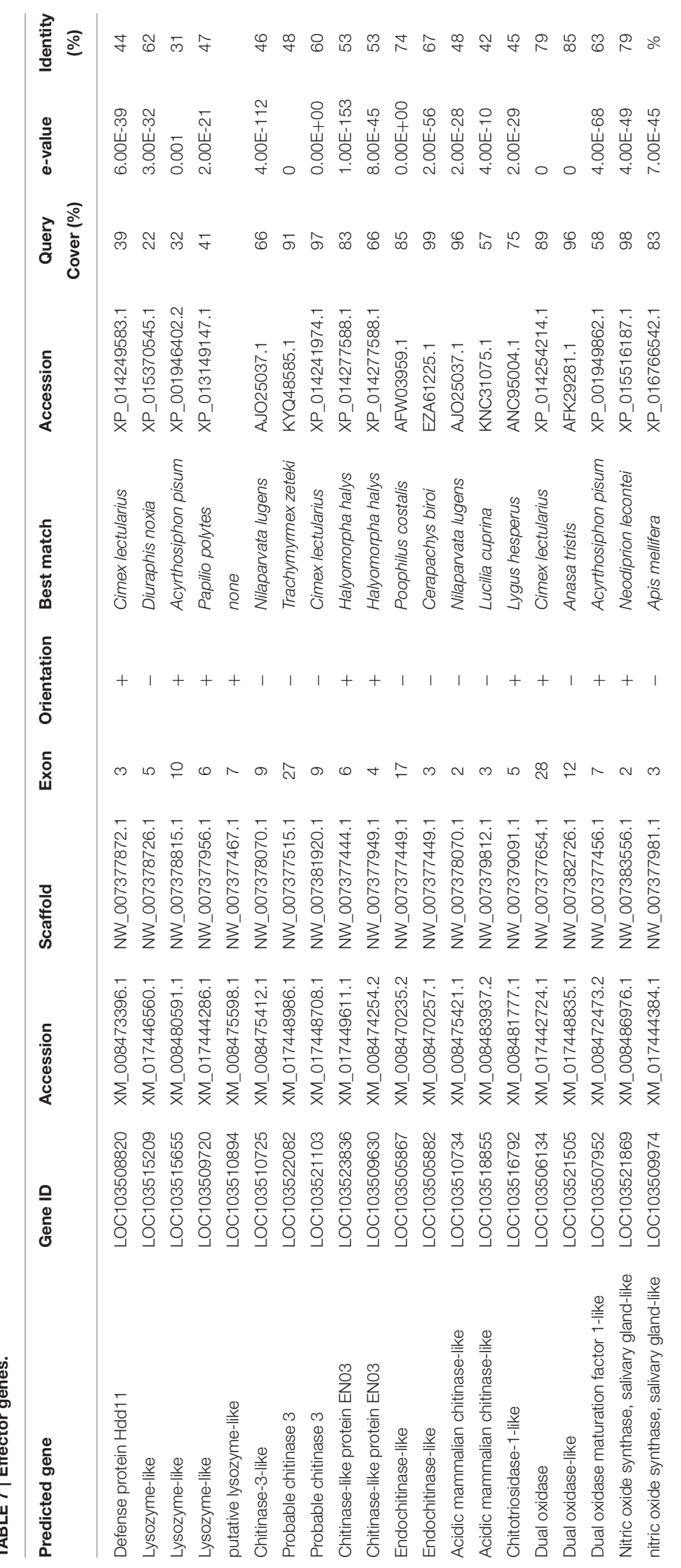


two type $\mathrm{V}$ chitinases that are secreted into the hemolymph following immune challenge and assist in the proliferation or recruitment of hemocytes and phagocytosis of invading bacteria (Shi and Paskewitz, 2004). Interestingly, these chitinase-like proteins are upregulated in the presence of bacteria but not fungi, although fungi have chitin cell walls (Shi and Paskewitz, 2004). Several chitinase-like proteins were predicted in D. citri (Table 7). The majority of these proteins are likely involved in molting, as D. citri do no feed on chitinous material and do not produce a peritrophic matrix.

\section{Detoxification}

Glutathione-s-transferases (GST) are a family of detoxification enzymes found in insects and almost all animals. GSTs detoxify exogenous compounds, including plant and microbial toxins, and pesticides (Kostaropoulos et al., 2001; Ortelli et al., 2003). In addition to detoxification, GSTs function in response to oxidative stress. Reactive oxygen compounds produced in response to microbial challenge are also cytotoxic to host tissues (Ranson and Hemingway, 2005). Insect GSTs were originally classified into type- 1 and type-2, but further studies have broken these into delta, epsilon, omega, theta, and zeta groups (Ranson and Hemingway, 2005).

Ten GSTs were identified in D. citri (Table S2). In a phylogenetic comparison to identify GST group, two sequences aligned with microsomal, two with epsilon, two with delta, and three with sigma type GSTs (Figure S2). One D. citri GST did not align to any classified GSTs used in the analysis. No $D$. citri GSTs showed similarity to zeta, omega, or theta types. Kumar et al. (2003) reported that impaired GST function in a strain of A. gambiae reduced their ability to acquire Plasmodium parasites due to the oxidative stress inducing conditions favorable to melanin encapsulation. In $D$. citri, induction of high oxidative stress may inhibit acquisition of CLas, thus GSTs could be a target for future research to prevent or reduce CLas transmission. Further investigations will determine the role of these GST genes in D. citri immune function and pesticide detoxification.

\section{CONCLUSIONS}

Current research on the innate immune system of insects has primarily focused on Drosophila and human disease vectors such as Anopheles mosquitoes. Only recently has the immune function in hemimetabolous insects, such as A. pisum, N. lugens, and $P$. humanus been explored (Ursic-Bedoya and Lowenberger, 2007; Gerardo et al., 2010; Kim et al., 2011; Bao et al., 2013). Interestingly, A. pisum, R. prolixus, and P. humanus have reduced immune systems as compared with holometabolous insects, while the $N$. lugens immune system appears similar to that of higher-order insects (Ursic-Bedoya and Lowenberger, 2007; Gerardo et al., 2010; Kim et al., 2011; Bao et al., 2013). Predicting the immune system defenses of $D$. citri is challenging, given the disparity among known Hemipteran immune genes. Annotation of the D. citri draft genome indicates that D. citri has a reduced innate immune system. In particular, genes related to the recognition of invading microorganisms, the Imd signaling pathway, and most antimicrobial peptides were absent. Although most insect genomes available for comparison are distantly related, and immune genes have high rates of evolution, these genes were identified in N. lugens. Furthermore, Drosophila gene sequences were used to identify immune genes in even more distantly-related arthropods, such as Ixodes scapularis (Schmid-Hempel, 2005; Bao et al., 2013; Smith and Pal, 2014). It is unlikely that the absence of these genes in D. citri is due to the high sequence divergence observed among immune genes.

D. citri may have a limited capacity for recognizing and eliminating the Gram-negative $\alpha$-proteobacterial plant pathogen, Candidatus Liberibacter asiaticus, due to the absence of an Imd pathway (Kleino and Silverman, 2014). Although missing the pathway, CLas titers may decline over time in adult D. citri (Pelz-Stelinski et al., 2010). The reduction in titer could imply that alternate immune pathways or defenses are used by $D$. citri, such as cellular immune responses. Nymphs acquire CLas more efficiently than adults, suggesting that immune response may vary with life stage (Inoue et al., 2009; Pelz-Stelinski et al., 2010).

Altincicek et al. (2008) proposed three hypotheses for the reduced immune system found in A. pisum: A. pisum encounter few pathogenic microorganisms in their diet; energy that would be used toward an immune response is allocated to reproductive effort; or the reduced immune system is due to, or the result of, $A$. pisum's associated obligate and facultative bacterial symbionts.

The hypothesis that the A. pisum reduced immune system is a function of diet is based on comparisons to insects such as Drosophila, which live and feed on decaying materials, are exposed to more microorganisms, and have more robust innate immune systems. Insects that feed on phloem are exposed to far fewer microorganisms, thus innate immune defenses are less important (Altincicek et al., 2008). This hypothesis is unlikely, as Sitophilus weevil juvenile stages develop within the sterile interior of cereal grains but exhibit robust immune defenses (Anselme et al., 2008). Additionally, A. pisum can acquire lethal Pseudomonas syringae, a pathogenic epiphyte, from leaf surfaces when probing, indicating that their reduced immune capabilities are not directly related to their feeding habits or environment (Stavrinides et al., 2009).

Immune responses are costly, and trade-offs occur between immune response and reproductive effort (Sheldon and Verhulst, 1996). Evidence of the reproductive cost in insects is apparent, where after an immune challenge, hatch rate and reproductive attempts decrease, as in mosquitoes (Contreras-Garduño et al., 2014). Time of immune challenge can also impact the allocation away from immune response to reproductive effort, evident in locusts, where newly-emerged adults produce eggs soon after immune challenge, while older adults do not, indicating an age-related immune focus (Blanford and Thomas, 2001). Specificity of reproductive costs due to immune challenge occur in A. pisum. Exposure to fungi reduces fecundity, while exposure to Gram-negative bacteria does not (Barribeau et al., 2014). Sex can also impact the degree of immune response, as in Gryllus texensis, where sexually mature females maintain 
or display an increase in immunocompetence, compared to a decrease among sexually active males (Adamo et al., 2001).

The absence of Imd pathways and antimicrobial peptides in A. pisum and D. citri may be associated with the complex relationships these insects have with bacterial symbionts. Primary symbionts facilitate exploitation of niche resources that are otherwise unavailable to their insect host. Endosymbionts may share metabolic pathways to produce essential amino acids lacking in the insect diet, such as Candidatus Carsonella ruddii and Buchnera aphidicola symbionts of psyllids and aphids, respectively (Wilson et al., 2006; Dahan et al., 2015). They may also aid in the breakdown of cellulose into accessible sugars, as in the complexes of bacteria and yeast found in termite guts. Secondary symbionts are not essential to an insect's survival, but can serve beneficial functions, such as increasing heat tolerance, providing protection from parasitoids, or aiding in metabolism during periods of nutritional stress (Montllor et al., 2002; Oliver et al., 2003; Su et al., 2014). Secondary symbionts are also involved in insect immunity (Eleftherianos et al., 2013). The A. pisum secondary symbiont, Regiella aphidicola, provides protection against the entomopathogenic fungus, Pandora neoaphidis (Scarborough et al., 2005; Oliver et al., 2008). Wolbachia, reported in D. citri, are bacteria known to activate or prime the immune system of mosquitoes, providing an increased basal level of immunity and resistance (Moreira et al., 2009). Candidatus Proftella armatura occur in D. citri bacteriocytes and produce cytotoxic polyketide toxins (Nakabachi et al., 2013). Endosymbionts that escape the bacteriocyte and infect surrounding tissues may silence AMP production, as in Sitophilus beetles. Toxins produced by Proftella may be associated with regulating endosymbionts as an alternative to insect-produced AMPs (Login et al., 2011).

The absence of putative essential immune genes in $D$. citri supports what may be a common feature among the Hemiptera. Altincicek et al. (2008) discussed three hypotheses to explain the reduced immune system found in aphids, the most probable being that the reduced immune defenses aided in the evolution of complex symbiotic relationships with bacteria. All sapfeeding Hemiptera require symbiotic bacteria or fungi that participate in the production of essential amino acids absent in these insects' diets. Whether the loss of immune function allowed for the colonization of these beneficial bacteria, or the introduction of these bacteria led to the loss of immune function, is not known. This adaptation likely opened new niches for sap-feeding insects and acted as a driver in their speciation. Secondarily, some symbionts provide A. pisum with protection from parasitoids or fungi, increasing the insect' fitness to ensure their passage to the next generation. The dynamics of these relationships are poorly understood. Knowledge of these interactions is primarily based on studies of A. pisum, an insect with unusual reproductive behavior that may not be truly representative of all Hemiptera. Our observation that D. citri also lack the Imd pathway offers another model organism for investigating the effect of a reduced immune system on insect survival, and the contribution of symbionts to insect immunity. Finally, immune reduction in $D$. citri may contribute to their competence as vectors of CLas by allowing this pathogen to invade the insect freely, thus facilitating transmission.

\section{AUTHOR CONTRIBUTIONS}

All authors contributed equally to this work. AA conducted the gene search and secondary BLAST survey and wrote the main paper. WH led the genome sequencing. All authors discussed the results and implications and commented on the manuscript at all stages.

\section{FUNDING}

The Florida Citrus Research and Development Foundation, Inc, 2011 (Project \# 05-021). Supported by grants from: USDA-ARS 2010-2011. The Florida Citrus Production Research Advisory Council, 2008. The BioScience Division, Los Alamos National Laboratory, NM, 2011-2012. The Citrus Research Board, 2012.

\section{ACKNOWLEDGMENTS}

The authors would like to thank the technical staff at both the USDA and UF/IFAS centers who contributed to sequencing the D. citri genome. Additional thanks to A. Kelley, C. Chu, T. Gill, D. Stockton, and H. Shugart for providing guidance and editing support.

\section{SUPPLEMENTARY MATERIAL}

The Supplementary Material for this article can be found online at: http://journal.frontiersin.org/article/10.3389/fphys. 2016.00570/full\#supplementary-material

Figure S1 | A phylogenetic comparison of $D$. citri predicted lysozymes with categorized lysozymes form other insects. The phylogenetic tree was constructed using the Geneious (Version 7.1, Kearse et al., 2012) Tree Builder. Branch labels signify substitutions per site. Sequences used are listed in Table S4. Aa, Aedes aegyptii; Ag, Anopheles gambiae; NI, Nilaparvata lugens; Dc, Diaphorina citri.

Figure S2 | A phylogenetic comparison $D$. citri glutathione s-transferases with categorized GSTs from other insects. The phylogenetic tree was constructed using the Geneious (Version 7.1, Kearse et al., 2012) Tree Builder. Branch labels signify substitutions per site. Sequences used are listed in Table S5. Dm, Drosophila melanogaster; Ap, Acyrthosiphon pisum; NI, Nilaparvata lugens; Bm, Bombyx mori; Dc, Diaphorina citri; Tm, Tenebrio molitor.

Table S1 | Leucine rich repeat containing protein genes.

Table S2 | Free radical defense associated genes.

Table S3 | Sequences used to create the phylogenetic tree in Figure 2.

Table S4 | List of sequences used in Figure S1.

Table S5 | List of sequences used in Figure S2. 


\section{REFERENCES}

Adamo, S. A., Jensen, M., and Younger, M. (2001). Changes in lifetime immunocompetence in male and female Gryllus texensis (formerly G. integer): trade-offs between immunity and reproduction. Anim. Behav. 62, 417-425. doi: 10.1006/anbe.2001.1786

Agaisse, H., and Perrimon, N. (2004). The roles of JAK/STAT signaling in Drosophila immune responses. Immunol. Rev. 198, 72-82. doi: 10.1111/j.01052896.2004.0133.x

Agaisse, H., Petersen, U.-M., Boutros, M., Mathey-Prevot, B., and Perrimon, N. (2003). Signaling role of hemocytes in Drosophila JAK/STAT-dependent response to septic injury. Dev. Cell 5, 441-450. doi: 10.1016/S15345807(03)00244-2

Aggarwal, K., and Silverman, N. (2008). Positive and negative regulation of the Drosophila immune response. BMB Rep. 41, 267-277. doi: 10.5483/BMBRep. 2008.41.4.267

Altincicek, B., Gross, J., and Vilcinskas, A. (2008). Wounding-mediated gene expression and accelerated viviparous reproduction of the pea aphid Acyrthosiphon pisum. Insect Mol. Biol. 17, 711-716. doi: 10.1111/j.1365-2583. 2008.00835.x

Ammar, E.-D., Shatters, R. G. Jr., Lynch, C., and Hall, D. G. (2011). Detection and relative titer of Candidatus Liberibacter asiaticus in the salivary glands and alimentary canal of Diaphorina citri (Hemiptera: Psyllidae) vector of citrus huanglongbing disease. Ann. Entom. Soc. Amer. 104, 526-533. doi: 10.1603/ AN10134

Anselme, C., Pérez-Brocal, V., Vallier, A., Vincent-Monegat, C., Charif, D., Latorre, A., et al. (2008). Identification of the Weevil immune genes and their expression in the bacteriome tissue. BMC Biol. 6:43. doi: 10.1186/1741-7007-6-43

Apidianakis, Y., Mindrinos, M. N., Xiao, W., Lau, G. W., Baldini, R. L., Davis, R. W., et al. (2005). Profiling early infection responses: Pseudomonas aeruginosa eludes host defenses by suppressing antimicrobial peptide gene expression. Proc. Natl. Acad. Sci. U.S.A. 102, 2573-2578. doi: 10.1073/pnas.0409588102

Arai, I., Ohta, M., Suzuki, A., Tanaka, S., Yoshizawa, Y., and Sato, R. (2013). Immunohistochemical analysis of the role of hemocytin in nodule formation in the larvae of the silkworm, Bombyx mori. J. Insect Sci. 13, 125-113. doi: 10. 1673/031.013.12501

Arakane, Y., and Muthukrishnan, S. (2009). Insect chitinase and chitinase-like proteins. Cell. Mol. Life Sci. 67, 201-216. doi: 10.1007/s00018-009-0161-9

Arnot, C. J., Gay, N. J., and Gangloff, M. (2010). Molecular mechanism that induces activation of Spätzle, the ligand for the Drosophila Toll receptor. J. Biol. Chem. 285, 19502-19509. doi: 10.1074/jbc.M109.098186

Aubert, B. (1987). Trioza erytreae Del Guercio and Diaphorina citri Kuwayama (Homoptera: Psylloidea), the two vectors of citrus greening disease: biological aspects and possible control strategies. Fruits 42, 149-162.

Avery, P. B., Hunter, W. B., Hall, D. G., Jackson, M. A., Powell, C. A., and Rogers, M. E. (2009). Diaphorina citri (Hemiptera: Psyllidae) infection and dissemination of the entomopathogenic fungus Isaria fumosorosea (Hypocreales: Cordycipitaceae) under laboratory conditions. Fla. Entomol. 92, 608-618. doi: 10.1653/024.092.0413

Avery, P. B., Wekesa, V. W., Hunter, W. B., Hall, D. G., McKenzie, C. L., Osborne, L. S., et al. (2011). Effects of the fungus Isaria fumosorosea (Hypocreales: Cordycipitaceae) on reduced feeding and mortality of the Asian citrus psyllid, Diaphorina citri (Hemiptera: Psyllidae). Biocontrol Sci. Technol. 21, 1065-1078. doi: 10.1080/09583157.2011.596927

Bao, Y.-Y., J., Xue, Wu, W.-J., Wang, Y., Lv, Z.-Y., and Zhang, C.-X. (2011). An immune-induced Reeler protein is involved in the Bombyx mori melanization cascade. Insect Biochem. Mol. Biol. 41, 696-706. doi: 10.1016/j.ibmb.2011. 05.001

Bao, Y.-Y., Qu, L.-Y., Zhao, D., Chen, L.-B., Jin, H.-Y., Xu, L.-M., et al. (2013). The genome- and transcriptome-wide analysis of innate immunity in the brown planthopper, Nilaparvata lugens. BMC Genomics 14:160. doi: 10.1186/14712164-14-160

Barribeau, S. M., Parker, B. J., and Gerardo, N. M. (2014). Exposure to natural pathogens reveals costly aphid response to fungi but not bacteria. Ecol. Evol. 4, 488-493. doi: 10.1002/ece3.892

Baum, L. G., Garner, O. B., Schaefer, K., and Lee, B. (2014). Microbehost interactions are positively and negatively regulated by Galectin-Glycan interactions. Front. Immunol. 5:284. doi: 10.3389/fimmu.2014.00284
Bischoff, V., Vignal, C., Boneca, I. G., Michel, T., Hoffmann, J. A., and Royet, J. (2004). Function of the Drosophila pattern-recognition receptor PGRP-SD in the detection of gram-positive bacteria. Nat. Immunol. 5, 1175-1180. doi: 10. 1038/ni1123

Blanford, S., and Thomas, M. B. (2001). Adult survival, maturation, and reproduction of the desert locust Schistocerca gregaria infected with the fungus Metarhizium anisopliae var acridum. J. Invertebr. Pathol. 78, 1-8. doi: 10.1006/ jipa.2001.5031

Brown, K. L., and Hancock, R. E. (2006). Cationic host defense (antimicrobial) peptides. Curr. Opin. Immunol. 18, 24-30. doi: 10.1016/j.coi.2005.11.004

Brown, S., Hu, N., and Hombria, J. (2001). Identification of the first invertebrate interleukin JAK/STAT receptor, the Drosophila gene domeless. Curr. Biol. 11, 1700-1705. doi: 10.1016/S0960-9822(01)00524-3

Buchon, N., Silverman, N., and Cherry, S. (2014). Immunity in Drosophila melanogaster - from microbial recognition to whole- organism physiology. Nat. Rev. Immunol. 14, 796-810. doi: 10.1038/nri3763

Cao, X., He, Y., Hu, Y., Wang, Y., Chen, Y.-R., Bryant, B., et al. (2015). The immune signaling pathways of Manduca sexta. Insect Biochem. Mol. Biol. 62, 64-74. doi: 10.1016/j.ibmb.2015.03.006

Cerenius, L., Lee, B. L., and Söderhäll, K. (2008). The proPO-system: pros and cons for its role in invertebrate immunity. Trends Immunol. 29, 263-271. doi: 10. 1016/j.it.2008.02.009

Chang, H.-J., Dhanasingh, I., Gou, X., Rice, A. M., and Dushay, M. S. (2012). Loss of Hemolectin reduces the survival of Drosophila larvae after wounding. Dev. Comp. Immunol. 36, 274-278. doi: 10.1016/j.dci.2011.04.009

Charroux, B., and Royet, J. (2010). Drosophila immune response: from systemic antimicrobial peptide production in fat body cells to local defense in the intestinal tract. Fly (Austin) 4, 40-47. doi: 10.4161/fly.4.1.10810

Choe, K.-M., Werner, T., Stöven, S., Hultmark, D., and Anderson, K. V. (2002). Requirement for a peptidoglycan recognition protein (PGRP) in relish activation and antibacterial immune responses in Drosophila. Science 296, 359-362. doi: 10.1126/science.1070216

Christophides, G. K., Zdobnov, E., Barillas-Mury, C., Birney, E., Blandin, S., Blass, C., et al. (2002). Immunity-related genes and gene families in Anopheles gambiae. Science 298, 159-165. doi: 10.1126/science.1077136

Colasanti, M., Gradoni, L., Mattu, M., Persichini, T., Salvati, L., Venturini, G., et al. (2002). Molecular bases for the anti-parasitic effect of NO. Int. J. Mol. Med. 9, 131-134. doi: 10.3892/ijmm.9.2.131

Contreras-Garduño, J., Rodríguez, M. C., Rodríguez, M. H., Alvarado-Delgado, A., and Lanz-Mendoza, H. (2014). Cost of immune priming within generations: trade-off between infection and reproduction. Microb. Infect. 16, 261-267. doi: 10.1016/j.micinf.2013.11.010

Cordaux, R., Bouchon, D., and Grève, P. (2011). The impact of endosymbionts on the evolution of host sex-determination mechanisms. Trends Genet. 27, 332-341. doi: 10.1016/j.tig.2011.05.002

Cronin, S. J., Nehme, N. T., Limmer, S., Liégeois, S., Pospisilik, J. A., Schramek, D., et al. (2009). Genome-wide RNAi screen identifies genes involved in intestinal pathogenic bacterial infection. Science 325, 340-343. doi: 10.1126/ science. 1173164

Dahan, R. A., Duncan, R. P., Wilson, A. C. C., and Dávalos, L. M. (2015). Amino acid transporter expansions associated with the evolution of obligate endosymbiosis in sap-feeding insects (Hemiptera: sternorrhyncha). BMC Evol. Biol. 15:52. doi: 10.1186/s12862-015-0315-3

Dobson, A. J., Purves, J., Kamysz, W., and Rolff, J. (2013). Comparing selection on $S$. aureus between antimicrobial peptides and common antibiotics. PLOS ONE 8:e76521. doi: 10.1371/journal.pone.0076521

Dong, Y., Cirimotich, C. M., Pike, A., Chandra, R., and Dimopoulos, G. (2012a). Anopheles NF-кB-regulated splicing factors direct pathogen-specific repertoires of the hypervariable pattern recognition receptor AgDscam. Cell Host Microbe 12, 521-530. doi: 10.1016/j.chom.2012.09.004

Dong, Y., Morton, J. C., Morton, J. C. Jr., Ramirez, J. L., Souza-Neto, J. A., and Dimopoulos, G. (2012b). The entomopathogenic fungus Beauveria bassiana activate toll and JAK-STAT pathway-controlled effector genes and anti-dengue activity in Aedes aegypti. Insect Biochem. Mol. Biol. 42, 126-132. doi: 10.1016/j. ibmb.2011.11.005

Dong, Y., Taylor, H. E., and Dimopoulos, G. (2006). AgDscam, a hypervariable immunoglobulin domain-containing receptor of the Anopheles gambiae innate immune system. PLoS Biol. 4:e229. doi: 10.1371/journal.pbio.0040229.st001 
Dostert, C., Jouanguy, E., Irving, P., Troxler, L., Galiana-Arnoux, D., Hetru, C., et al. (2005). The Jak-STAT signaling pathway is required but not sufficient for the antiviral response of Drosophila. Nat. Immunol. 6, 946-953. doi: 10.1038/ ni1237

Dziarski, R., and Gupta, D. (2005). Peptidoglycan recognition in innate immunity. J. Endotoxin Res. 11, 304-310. doi: 10.1177/09680519050110050801

Dziarski, R., and Gupta, D. (2006). The peptidoglycan recognition proteins (PGRPs). Genome Biol. 7:232. doi: 10.1186/gb-2006-7-8-232

Ekengren, S., and Hultmark, D. (2001). A family of Turandot-related genes in the humoral stress response of Drosophila. Biochem. Biophys. Res. Commun. 284, 998-1003. doi: 10.1006/bbrc.2001.5067

Elbashir, S. M., Harborth, J., Lendeckel, W., and Yalcin, A. (2001). Duplexes of 21-nucleotide RNAs mediate RNA interference in cultured mammalian cells. Nature 411, 494-498. doi: 10.1038/35078107

Eleftherianos, I., Atri, J., Accetta, J., and Castillo, J. C. (2013). Endosymbiotic bacteria in insects: guardians of the immune system? Front. Physiol. 4:46. doi: 10.3389/fphys.2013.00046

El-Shesheny, I., Hajeri, S., El-Hawary, I., Gowda, S., and Killiny, N. (2013). Silencing abnormal wing disc gene of the Asian citrus psyllid, Diaphorina citri disrupts adult wing development and increases nymph mortality. PLoS ONE 8:e65392. doi: 10.1371/journal.pone.0065392

Fereres, A., and Moreno, A. (2009). Behavioural aspects influencing plant virus transmission by homopteran insects. Virus Res. 141, 158-168. doi: 10.1016/j. virusres.2008.10.020

Foley, E., and O'Farrell, P. H. (2003). Nitric oxide contributes to induction of innate immune responses to Gram-negative bacteria in Drosophila. Genes Dev. 17, 115-125. doi: 10.1101/gad.1018503

Fraiture, M., Baxter, R. H., Steinert, S., Chelliah, Y., Frolet, C., Quispe-Tintaya, W., et al. (2009). Two mosquito LRR proteins function as complement control factors in the TEP1-mediated killing of Plasmodium. CHOM 5, 273-284. doi: 10.1016/j.chom.2009.01.005

Gandhe, A. S., John, S. H., and Nagaraju, J. (2007). Noduler, a novel immune upregulated protein mediates nodulation response in insects. J. Immunol. 179, 6943-6951. doi: 10.4049/jimmunol.179.10.6943

Garver, L. S., Wu, J., and Wu, L. P. (2006). The peptidoglycan recognition protein PGRP-SC1a is essential for Toll signaling and phagocytosis of Staphylococcus aureus in Drosophila. Proc. Natl. Acad. Sci. U.S.A. 103, 660-665. doi: 10.1073/ pnas.0506182103

Gerardo, N. M., Altincicek, B., Anselme, C., Atamian, H., Barribeau, S. M., de Vos, M., et al. (2010). Immunity and other defenses in pea aphids, Acyrthosiphon pisum. Genome Biol. 11:R21. doi: 10.1186/gb-2010-11$2-\mathrm{r} 21$

Geuking, P., Narasimamurthy, R., Lemaitre, B., Basler, K., and Leulier, F. (2009). A non-redundant role for Drosophila Mkk4 and Hemipterous/Mkk7 in TAK1mediated activation of JNK. PLOS ONE 4:e7709. doi: 10.1371/journal.pone. 0007709

Gobert, V. (2003). Dual activation of the Drosophila Toll pathway by two pattern recognition receptors. Science 302, 2126-2130. doi: 10.1126/science.1085432

González-Santoyo, I., and Córdoba-Aguilar, A. (2011). Phenoloxidase: a key component of the insect immune system. Entomol. Exp. Appl. 142, 1-16. doi: 10.1111/j.1570-7458.2011.01187.x

Gottar, M., Gobert, V., Matskevich, A. A., Reichhart, J.-M., Wang, C., Butt, T. M., et al. (2006). Dual detection of fungal infections in Drosophila via recognition of glucans and sensing of virulence factors. Cell 127, 1425-1437. doi: 10.1016/j. cell.2006.10.046

Gottar, M., Gobert, V., Michel, T., Belvin, M., Duyk, G., Hoffmann, J. A., et al. (2002). The Drosophila immune response against Gram-negative bacteria is mediated by a peptidoglycan recognition protein. Nature 416, 640-644. doi: 10 . 1038 /nature734

Gross, I., Georgel, P., Kappler, C., Reichhart, J. M., and Hoffmann, J. A. (1996). Drosophila immunity: a comparative analysis of the Rel proteins dorsal and Dif in the induction of the genes encoding diptericin and cecropin. Nucleic Acids Res. 24, 1238-1245.

Ha, E. M., Oh, C. T., Bae, Y. S., and Lee, W. J. (2005). A direct role for dual oxidase in Drosophila gut immunity. Science 310, 847-850. doi: 10.1126/ science. 1117311

Halbert, S. E., and Manjunath, K. L. (2004). Asian citrus psyllids (Sternorrhyncha: Psyllidae) and greening disease of citrus: a literature review and assessment of risk in Florida. Fla. Entomol. 87, 330-353. doi: 10.1653/00154040(2004)087[0330:ACPSPA]2.0.CO;2

Hall, D. G., Richardson, M. L., Ammar, E.-D., and Halbert, S. E. (2013). Asian citrus psyllid, Diaphorina citri, vector of citrus huanglongbing disease. Entomol. Exp. Appl. 146, 207-223. doi: 10.1111/eea.12025

Hammond, S. M., Boettcher, S., Caudy, A. A., Kobayashi, R., and Hannon, G. J. (2001). Argonaute2, a link between genetic and biochemical analyses of RNAi. Science 293, 1146-1150. doi: 10.1126/science.1064023

Hancock, R. E., and Diamond, G. (2000). The role of cationic antimicrobial peptides in innate host defences. Trends Microbiol. 8, 402-410. doi: 10.1016/ S0966-842X(00)01823-0

Harrison, D. A., McCoon, P. E., Binari, R., Gilman, M., and Perrimon, N. (1998). Drosophila unpaired encodes a secreted protein that activates the JAK signaling pathway. Genes Dev. 12, 3252-3263. doi: 10.1101/gad.12.20.3252

Hashimoto, C., Hudson, K. L., and Anderson, K. V. (1988). The Toll gene of Drosophila, required for dorsal-ventral embryonic polarity, appears to encode a transmembrane protein. Cell 52, 269-279.

Hedengren, M., Asling, B., Dushay, M. S., Ando, I., Ekengren, S., Wihlborg, M., et al. (1999). Relish, a central factor in the control of humoral but not cellular immunity in Drosophila. Mol. Cell 4, 827-837.

Hetru, C., and Hoffmann, J. A. (2009). NFk- B in the immune response of Drosophila. Cold Spring Harb. Perspect. Biol. 1:a000232. doi: 10.1101/ cshperspect.a000232

Hillyer, J. F., Schmidt, S. L., and Christensen, B. M. (2003). Hemocyte-mediated phagocytosis and melanization in the mosquito Armigeres subalbatus following immune challenge by bacteria. Cell Tissue Res. 313, 117-127. doi: 10.1007/ s00441-003-0744-y

Hoffmann, J. A., and Reichhart, J.-M. (2002). Drosophila innate immunity: an evolutionary perspective. Nat. Immunol. 3, 121-126. doi: 10.1038/ni0202-121

Hou, S. X., Zheng, Z., Chen, X., and Perrimon, N. (2002). The Jak/STAT pathway in model organisms: emerging roles in cell movement. Dev. Cell 3, 765-778. doi: 10.1016/S1534-5807(02)00376-3

Hughes, R. C. (2001). Galectins as modulators of cell adhesion. Biochimie 83, 667-676. doi: 10.1016/S0300-9084(01)01289-5

Hunter, W. B., Reese, J., and International Psyllid Genome Consortium (2014). The Asian citrus psyllid genome (Diaphorina citri, Hemiptera). J. Citrus Pathol. 1, 143.

Imler, J.-L., and Hoffmann, J. A. (2001). Toll receptors in innate immunity. Trends Cell Biol. 11, 304-311. doi: 10.1016/S0962-8924(01)02004-9

Inoue, H., Ohnishi, J., Ito, T., Tomimura, K., Miyata, S., Iwanami, T., et al. (2009). Enhanced proliferation and efficient transmission of Candidatus Liberibacter asiaticus by adult Diaphorina citri after acquisition feeding in the nymphal stage. Ann. Appl. Biol. 155, 29-36. doi: 10.1111/j.1744-7348.2009.00317.x

Ip, Y. T., Reach, M., Engstrom, Y., Kadalayil, L., Cai, H., González-Crespo, S., et al. (1993). Dif, a dorsal-related gene that mediates an immune response in Drosophila. Cell 75, 753-763.

Jiang, H., Ma, C., Lu, Z.-Q., and Kanost, M. R. (2004). $\beta$-1,3-Glucan recognition protein-2 ( $\beta$ GRP-2) from Manduca sexta: an acute-phase protein that binds $\beta$ 1,3-glucan and lipoteichoic acid to aggregate fungi and bacteria and stimulate prophenoloxidase activation. Insect Biochem. Mol. Biol. 34, 89-100. doi: 10. 1016/j.ibmb.2003.09.006

Kang, D., Liu, G., Lundström, A., Gelius, E., and Steiner, H. (1998). A peptidoglycan recognition protein in innate immunity conserved from insects to humans. Proc. Natl. Acad. Sci. U.S.A. 95, 10078-10082.

Kearse, M., Moir, R., Wilson, A., Stones-Havas, S., Cheung, M., Sturrock, S., et al. (2012). Geneious basic: an integrated and extendable desktop software platform for the organization and analysis of sequence data. Bioinformatics 28 , 1647-1649. doi: 10.1093/bioinformatics/bts199

Kidd, S. (1992). Characterization of the Drosophila cactus locus and analysis of interactions between cactus and dorsal proteins. Cell 71, 623-635.

Killiny, N., Hajeri, S., Tiwari, S., Gowda, S., and Stelinski, L. L. (2014). Doublestranded RNA uptake through topical application, mediates silencing of five CYP4 genes and suppresses insecticide resistance in Diaphorina citri. PLoS ONE 9:e110536. doi: 10.1371/journal.pone.0110536

Kim, J. H., Min, J. S., Kang, J. S., Kwon, D. H., Yoon, K. S., Strycharz, J., et al. (2011). Comparison of the humoral and cellular immune responses between body and head lice following bacterial challenge. Insect Biochem. Mol. Biol. 41, 332-339. doi: 10.1016/j.ibmb.2011.01.011 
Kingsolver, M. B., Huang, Z., and Hardy, R. W. (2013). Insect antiviral innate immunity: pathways, effectors, and connections. J. Mol. Biol. 425, 4921-4936. doi: 10.1016/j.jmb.2013.10.006

Kleino, A., and Silverman, N. (2014). The Drosophila IMD pathway in the activation of the humoral immune response. Dev. Comp. Immunol. 42, 25-35. doi: 10.1016/j.dci.2013.05.014

Kostaropoulos, I., Papadopoulos, A. I., Metaxakis, A., Boukouvala, E., and Papadopoulou-Mourkidou, E. (2001). Glutathione S-transferase in the defence against pyrethroids in insects. Insect Biochem. Mol. Biol. 31, 313-319. doi: 10. 1016/S0965-1748(00)00123-5

Kotani, E., Yamakawa, M., Iwamoto, S., Tashiro, M., Mori, H., Sumida, M., et al. (1995). Cloning and expression of the gene of hemocytin, an insect humoral lectin which is homologous with the mammalian von Willebrand factor. Biochim. Biophys. Acta 1260, 245-258.

Kumar, S., Christophides, G. K., Cantera, R., Charles, B., Han, Y. S., Meister, S., et al. (2003). The role of reactive oxygen species on Plasmodium melanotic encapsulation in Anopheles gambiae. Proc. Natl. Acad. Sci. U.S.A. 100, 14139-14144. doi: 10.1073/pnas.2036262100

Kuraishi, T., Binggeli, O., Opota, O., Buchon, N., and Lemaitre, B. (2011). Genetic evidence for a protective role of the peritrophic matrix against intestinal bacterial infection in Drosophila melanogaster. Proc. Natl. Acad. Sci. U.S.A. 108, 15966-15971. doi: 10.1073/pnas.1105994108

Lagueux, M., Perrodou, E., Levashina, E. A., Capovilla, M., and Hoffmann, J. A. (2000). Constitutive expression of a complement-like protein in Toll and JAK gain-of-function mutants of Drosophila. Proc. Natl. Acad. Sci. U.S.A. 97, 11427-11432. doi: 10.1073/pnas.97.21.11427

Lavine, M. D., and Strand, M. R. (2002). Insect hemocytes and their role in immunity. Insect Biochem. Mol. Biol. 32, 1295-1309. doi: 10.1016/S09651748(02)00092-9

Lesch, C., Goto, A., Lindgren, M., Bidla, G., Dushay, M. S., and Theopold, U. (2007). A role for Hemolectin in coagulation and immunity in Drosophila melanogaster. Dev. Comp. Immunol. 31, 1255-1263. doi: 10.1016/j.dci.2007. 03.012

Ligoxygakis, P., Pelte, N., Hoffmann, J. A., and Reichhart, J.-M. (2002a). Activation of Drosophila Toll during fungal infection by a blood serine protease. Science 297, 114-116. doi: 10.1126/science.1072391

Ligoxygakis, P., Pelte, N., Ji, C., Leclerc, V., Duvic, B., Belvin, M., et al. (2002b). A serpin mutant links Toll activation to melanization in the host defence of Drosophila. EMBO J. 21, 6330-6337. doi: 10.1093/emboj/cdf661

Ling, E., Ao, J., and Yu, X.-Q. (2008). Nuclear translocation of immulectin-3 stimulates hemocyte proliferation. Mol. Immunol. 45, 2598-2606. doi: 10.1016/ j.molimm.2007.12.021

Liu, H., Jiravanichpaisal, P., Cerenius, L., Lee, B. L., Söderhäll, I., and Söderhäll, K. (2007). Phenoloxidase is an important component of the defense against Aeromonas hydrophila infection in a crustacean, Pacifastacus leniusculus. J. Biol. Chem. 282, 33593-33598. doi: 10.1074/jbc.M706113200

Liu, Q., Rand, T. A., Kalidas, S., Du, F., Kim, H.-E., Smith, D. P., et al. (2003). R2D2, a bridge between the initiation and effector steps of the Drosophila RNAi pathway. Science 301, 1921-1925. doi: 10.1126/science.1088710

Liu, X., Jiang, F., Kalidas, S., Smith, D., and Liu, Q. (2006). Dicer-2 and R2D2 coordinately bind siRNA to promote assembly o the siRISC complexes. RNA 12, 1514-1520. doi: $10.1261 /$ rna.101606

Login, F. H., Balmand, S., Vallier, A., Vincent-Monégat, C., Vigneron, A., WeissGayet, M., et al. (2011). Antimicrobial peptides keep insect endosymbionts under control. Science 334, 362-365. doi: 10.1126/science.1209728

Luckhart, S., Vodovotz, Y., Cui, L., and Rosenberg, R. (1998). The mosquito Anopheles stephensi limits malaria parasite development with inducible synthesis of nitric oxide. Proc. Natl. Acad. Sci. U.S.A. 95, 5700-5705.

Luo, H., Rose, P., Roberts, T., and Dearolf, C. (2002). The Hopscotch Jak kinase requires the Raf pathway to promote blood cell activation and differentiation in Drosophila. Mol. Genet. Genomics 267, 57-63. doi: 10.1007/s00438-0010632-7

McLean, A. H. C., van Asch, M., Ferrari, J., and Godfray, H. C. (2011). Effects of bacterial secondary symbionts on host plant use in pea aphids. Proc. R. Soc. B 278, 760-766. doi: 10.1146/annurev-ento-112408-085305

McTaggart, S. J., Conlon, C., Colbourne, J. K., Blaxter, M. L., and Little, T. J. (2009). The components of the Daphnia pulex immune system as revealed by complete genome sequencing. BMC Genomics 10:175. doi: 10.1186/1471-2164-10-175
Mesquita, R. D., Vionette-Amaral, R. J., Lowenberger, C., Rivera-Pomar, R., Monteiro, F. A., Minx, P., et al. (2015). Genome of Rhodnius prolixus, an insect vector of Chagas disease, reveals unique adaptations to hematophagy and parasite infection. Proc. Natl. Acad. Sci. U.S.A. 112, 14936-1494. doi: 10.1073/ pnas. 1506226112

Michel, K., Budd, A., Pinto, S., Gibson, T. J., and Kafatos, F. C. (2005). Anopheles gambiae SRPN2 facilitates midgut invasion by the malaria parasite Plasmodium berghei. EMBO Rep. 6, 891-897. doi: 10.1038/sj.embor.7400478

Michel, T., Reichhart, J. M., Hoffmann, J. A., and Royet, J. (2001). Drosophila Toll is activated by Gram-positive bacteria through a circulating peptidoglycan recognition protein. Nature 414, 756-759. doi: 10.1038/414756a

Minakhina, S., Tan, W., and Steward, R. (2011). JAK/STAT and the GATA factor Pannier control hemocyte maturation and differentiation in Drosophila. Dev. Biol. 352, 308-316. doi: 10.1016/j.ydbio.2011.01.035

Mizutani, T., Kobayashi, M., Eshita, Y., Shirato, K., Kimura, T., Ako, Y., et al. (2003). Involvement of the JNK-like protein of the Aedes albopictus mosquito cell line, C6/36, in phagocytosis, endocytosis and infection of West Nile virus. Insect Mol. Biol. 12, 491-499. doi: 10.1046/j.1365-2583.2003.00435.x

Mohamed, A. A., Zhang, L., Dorrah, M. A., Elmogy, M., Yousef, H., Bassal, T. T. M., et al. (2016). Molecular characterization of a c-type lysozyme from the desert locust, Schistocerca gregaria (Orthoptera: Acrididae). Dev. Comp. Immunol. 61, 60-69. doi: 10.1016/j.dci.2016.03.018

Moncrieffe, M. C., Grossmann, J. G., and Gay, N. J. (2008). Assembly of oligomeric death domain complexes during Toll receptor signaling. J. Biol. Chem. 283, 33447-33454. doi: 10.1074/jbc.M805427200

Montllor, C. B., Maxmen, A., and Purcell, A. H. (2002). Facultative bacterial endosymbionts benefit pea aphids Acyrthosiphon pisum under heat stress. Ecol. Entomol. 27, 189-195. doi: 10.1046/j.1365-2311.2002.00393.x

Moreira, L. A., Iturbe-Ormaetxe, I., Jeffery, J. A., Lu, G., Pyke, A. T., Hedges, L. M., et al. (2009). A Wolbachia symbiont in Aedes aegypti limits infection with Dengue, Chikungunya, and Plasmodium. Cell 139, 1268-1278. doi: 10.1016/j. cell.2009.11.042

Nakabachi, A., Ueoka, R., Oshima, K., Teta, R., Mangoni, A., Gurgui, M., et al. (2013). Defensive bacteriome symbiont with a drastically reduced genome. Curr. Biol. 23, 1478-1484. doi: 10.1016/j.cub.2013.06.027

Nappi, A. J., Frey, F., and Carton, Y. (2005). Drosophila serpin 27A is a likely target for immune suppression of the blood cell-mediated melanotic encapsulation response. J. Insect Physiol. 51, 197-205. doi: 10.1016/j.jinsphys.2004.10.013

Oliver, K. M., Campos, J., Moran, N. A., and Hunter, M. S. (2008). Population dynamics of defensive symbionts in aphids. Proc. R. Soc. B 275, 293-299. doi: 10. 1111/j.1365-294X.2004.02203.x

Oliver, K. M., Russell, J. A., Moran, N. A., and Hunter, M. S. (2003). Facultative bacterial symbionts in aphids confer resistance to parasitic wasps. Proc. Natl. Acad. Sci. 100, 1803-1807. doi: 10.1073/pnas.0335320100

Ortelli, F., Rossiter, L. C., Vontas, J., Ranson, H., and Hemingway, J. (2003). Heterologous expression of four glutathione transferase genes genetically linked to a major insecticide-resistance locus from the malaria vector Anopheles gambiae. Biochem. J. 373, 957-963. doi: 10.1042/BJ 20030169

Pan, X., Zhou, G., Wu, J., Bian, G., Lu, P., Raikhel, A. S., et al. (2012). Wolbachia induces reactive oxygen species (ROS)-dependent activation of the Toll pathway to control dengue virus in the mosquito Aedes aegypti. Proc. Natl. Acad. Sci. U.S.A. 109, E23-E31. doi: 10.1073/pnas.1116932108/-/ DCSupplemental

Park, J.-W., Kim, C.-H., Kim, J.-H., Je, B.-R., Roh, K.-B., Kim, S.-J., et al. (2007). Clustering of peptidoglycan recognition protein-SA is required for sensing lysine-type peptidoglycan in insects. Proc. Natl. Acad. Sci. U.S.A. 104, 6602-6607. doi: 10.1073/pnas.0610924104

Pelz-Stelinski, K. S., Brlansky, R. H., Ebert, T. A., and Rogers, M. E. (2010) Transmission parameters for Candidatus Liberibacter asiaticus by Asian citrus psyllid (Hemiptera: Psyllidae). J. Econ. Entomol. 103, 1531-1541. doi: 10.1603/ EC10123

Pili-Floury, S., Leulier, F., Takahashi, K., Saigo, K., Samain, E., Ueda, R., et al. (2004). In vivo RNA interference analysis reveals an unexpected role for GNBP1 in the defense against Gram-positive bacterial infection in Drosophila adults. J. Biol. Chem. 279, 12848-12853. doi: 10.1074/jbc.M313324200

Rabinovich, G. A., Baum, L. G., Tinari, N., Paganelli, R., Natoli, C., Liu, F.-T., et al. (2002). Galectins and their ligands: amplifiers, silencers or tuners of the 
inflammatory response? Trends Immunol. 23, 313-320. doi: 10.1016/S14714906(02)02232-9

Rämet, M., Lanot, R., Zachary, D., and Manfruelli, P. (2002). JNK signaling pathway is required for efficient wound healing in Drosophila. Dev. Biol. 241, 145-156. doi: 10.1006/dbio.2001.0502

Rand, T. A., Ginalski, K., Grishin, N. V., and Wang, X. (2004). Biochemical identification of Argonaute 2 as the sole protein required for RNA-induced silencing complex activity. Proc. Natl. Acad. Sci. U.S.A. 101, 14385-14389. doi: 10.1073/pnas.0405913101

Ranson, H., and Hemingway, J. (2005). Mosquito glutathione transferases. Methods Enzymol. 401, 226-241. doi: 10.1016/S0076-6879(05)01014-1

Ratcliffe, N. A., and Gagen, S. J. (1976). Cellular defense reactions of insect hemocytes in vivo: nodule formation and development in Galleria mellonella and Pieris brassicae larvae. J. Invertebr. Pathol. 28, 373-382.

Reese, J., Christenson, M. K., Leng, N., Saha, S., Cantarel, B., Lindeberg, M., et al. (2014). Characterization of the Asian citrus psyllid transcriptome. J. Genomics 2, 54-58. doi: 10.7150/jgen.7692

Roh, K. B., Kim, C. H., Lee, H., Kwon, H. M., Park, J. W., Ryu, J. H., et al. (2009). Proteolytic cascade for the activation of the insect Toll pathway induced by the fungal cell wall component. J. Biol. Chem. 284, 19474-19481. doi: 10.1074/jbc. M109.007419

Roth, O., Joop, G., Eggert, H., Hilbert, J., Daniel, J., Schmid-Hempel, P., et al. (2010). Paternally derived immune priming for offspring in the red flour beetle, Tribolium castaneum. J. Anim. Ecol. 79, 403-413. doi: 10.1111/j.1365-2656. 2009.01617.x

Rutschmann, S., Jung, A. C., Hetru, C., Reichhart, J. M., Hoffmann, J. A., and Ferrandon, D. (2000). The Rel protein DIF mediates the antifungal but not the antibacterial host defense in Drosophila. Immunity 12, 569-580. doi: 10.1016/ S1074-7613(00)80208-3

Sackton, T. B., Lazzaro, B. P., Schlenke, T. A., Evans, J. D., Hultmark, D., and Clark, A. G. (2007). Dynamic evolution of the innate immune system in Drosophila. Nat. Genet. 39, 1461-1468. doi: 10.1038/ng2007.60

Scarborough, C. L., Ferrari, J., and Godfray, H. C. J. (2005). Aphid protected from pathogen by endosymbiont. Science 310, 1781-1781. doi: 10.1126/science. 1120180

Schleifer, K. H., and Kandler, O. (1972). Peptidoglycan types of bacterial cell walls and their taxonomic implications. Bacteriol. Rev. 36, 407-477.

Schmid-Hempel, P. (2005). Evolutionary ecology of insect immune defenses. Annu. Rev. Entomol. 50, 529-551. doi: 10.1146/annurev.ento.50.071803.130420

Schmucker, D., and Chen, B. (2009). Dscam and DSCAM: complex genes in simple animals, complex animals yet simple genes. Genes Dev. 23, 147-156. doi: 10. 1101/gad.1752909

Sheldon, B. C., and Verhulst, S. (1996). Ecological immunology: costly parasite defences and trade-offs in evolutionary ecology. Trends Ecol. Evol. (Amst.) 11, 317-321. doi: 10.1016/0169-5347(96)10039-2

Shi, L., and Paskewitz, S. M. (2004). Identification and molecular characterization of two immune-responsive chitinase-like proteins from Anopheles gambiae. Insect Mol. Biol. 13, 387-398. doi: 10.1111/j.0962-1075.2004.00496.x

Sim, S., Jupatanakul, N., and Dimopoulos, G. (2014). Mosquito immunity against arboviruses. Viruses 6, 4479-4504. doi: 10.3390/v6114479

Smith, A. A., and Pal, U. (2014). Immunity-related genes in Ixodes scapularisperspectives from genome information. Front Cell Infect Microbiol 4:116. doi: 10.3389/fcimb.2014.00116

Sorrentino, R. P., Melk, J. P., and Govind, S. (2004). Genetic analysis of contributions of dorsal group and JAK-Stat92E pathway genes to larval hemocyte concentration and the egg encapsulation response in Drosophila. Genetics 166, 1343-1356. doi: 10.1534/genetics.166.3.1343

Souza-Neto, J. A., Sim, S., and Dimopoulos, G. (2009). An evolutionary conserved function of the JAK-STAT pathway in anti-dengue defense. Proc. Natl. Acad. Sci. U.S.A. 106, 17841-17846. doi: 10.1073/pnas.0905006106

Stavrinides, J., McCloskey, J. K., and Ochman, H. (2009). Pea aphid as both host and vector for the phytopathogenic bacterium Pseudomonas syringae. Appl. Environ. Microbiol. 75, 2230-2235. doi: 10.1128/AEM. 02860-08

Su, Q., Xie, W., Wang, S., Wu, Q., Liu, B., Fang, Y., et al. (2014). The endosymbiont Hamiltonella increases the growth rate of its host Bemisia tabaci during periods of nutritional stress. PLoS ONE 9:e89002. doi: 10.1371/journal.pone.0089002. s001
Sun, H., Bristow, B. N., Qu, G., and Wasserman, S. A. (2002). A heterotrimeric death domain complex in Toll signaling. Proc. Natl. Acad. Sci. U.S.A. 99, 12871-12876. doi: 10.1073/pnas.202396399

Takehana, A., Katsuyama, T., Yano, T., Oshima, Y., Takada, H., Aigaki, T., et al. (2002). Overexpression of a pattern-recognition receptor, peptidoglycanrecognition protein-LE, activates imd/relish-mediated antibacterial defense and the prophenoloxidase cascade in Drosophila larvae. Proc. Natl. Acad. Sci. U.S.A. 99, 13705-13710. doi: 10.1073/pnas.212301199

Takehana, A., Yano, T., Mita, S., Kotani, A., Oshima, Y., and Kurata, S. (2004). Peptidoglycan recognition protein (PGRP)-LE and PGRP-LC act synergistically in Drosophila immunity. EMBO J. 23, 4690-4700. doi: 10.1038/sj.emboj. 7600466

Tang, H. (2009). Regulation and function of the melanization reaction in Drosophila. Fly (Austin). 3, 105-111. doi: 10.4161/fly.3.1.7747

Tauszig, S., Jouanguy, E., Hoffmann, J. A., and Imler, J. L. (2000). Toll-related receptors and the control of antimicrobial peptide expression in Drosophila. Proc. Natl. Acad. Sci. U.S.A. 97, 10520-10525. doi: 10.1073/pnas.180130797

Thao, M. L., Moran, N. A., Abbot, P., Brennan, E. B., Burckhardt, D. H., and Baumann, P. (2000). Cospeciation of psyllids and their primary prokaryotic endosymbionts. Appl. Environ. Microbiol. 66, 2898-2905. doi: 10.1128/AEM. 66.7.2898-2905.2000

Theopold, U., Schmidt, O., Söderhäll, K., and Dushay, M. S. (2004). Coagulation in arthropods: defence, wound closure and healing. Trends Immunol. 25, 289-294. doi: 10.1016/j.it.2004.03.004

Tian, Y.-Y., Liu, Y., Zhao, X.-F., and Wang, J.-X. (2009). Characterization of a C-type lectin from the cotton bollworm, Helicoverpa armigera. Dev. Comp. Immunol. 33, 772-779. doi: 10.1016/j.dci.2009.01.002

Tsuchida, T., Koga, R., and Fukatsu, T. (2004). Host plant specialization governed by facultative symbiont. Science 303, 1989-1989. doi: 10.1126/science.1094611

Tsuchida, T., Koga, R., Matsumoto, S., and Fukatsu, T. (2011). Interspecific symbiont transfection confers a novel ecological trait to the recipient insect. Biol. Lett. 7, 245-248. doi: 10.1098/rsbl.2010.0699

Ursic-Bedoya, R. J., and Lowenberger, C. A. (2007). Rhodnius prolixus: Identification of immune-related genes up-regulated in response to pathogens and parasites using suppressive subtractive hybridization. Dev. Comp. Immunol. 31, 109-120. doi: 10.1016/j.dci.2006.05.008

Valanne, S., Wang, J. H., and Rämet, M. (2011). The Drosophila Toll signaling pathway. J. Immunol. 186, 649-656. doi: 10.4049/jimmunol.1002302

Vallet-Gely, I., Lemaitre, B., and Boccard, F. (2008). Bacterial strategies to overcome insect defences. Nat. Rev. Micro 6, 302-313. doi: 10.1038/ nrmicrol 1870

Vyas, M., Fisher, T. W., He, R., Nelson, W., Yin, G., Cicero, J. M., et al. (2015). Asian citrus psyllid expression profiles suggest Candidatus Liberibacter asiaticusmediated alteration of adult nutrition and metabolism, and of nymphal development and immunity. PLOS ONE 10:e130328. doi: 10.1371/journal. pone. 0130328

Wang, G., Li, X., and Wang, Z. (2009). APD2: the updated antimicrobial peptide database and its application in peptide design. Nucleic Acids Res. 37, D933D937. doi: 10.1093/nar/gkn823

Wang, Y., Sumathipala, N., Rayaprolu, S., and Jiang, H. (2011). Recognition of microbial molecular patterns and stimulation of prophenoloxidase activation by a $\beta$-1,3-glucanase-related protein in Manduca sexta larval plasma. Insect Biochem. Mol. Biol. 41, 322-331. doi: 10.1016/j.ibmb.2011.01.010

Watson, F. L., Püttmann-Holgado, R., Thomas, F., Lamar, D. L., Hughes, M., Kondo, M., et al. (2005). Extensive diversity of Ig-superfamily proteins in the immune system of insects. Science 309, 1874-1878. doi: 10.1126/science. 1114233

Weber, A., Tauszig-Delamasure, S., Hoffmann, J. A., Lelievre, E., Gascan, H., Ray, K. P., et al. (2003). Binding of the Drosophila cytokine Spätzle to Toll is direct and establishes signaling. Nat. Immunol. 4, 794-800. doi: 10.1038/ni955

Werner, T., Borge-Renberg, K., Mellroth, P., Steiner, H., and Hultmark, D. (2003). Functional diversity of the Drosophila PGRP-LC gene cluster in the response to lipopolysaccharide and peptidoglycan. J. Biol. Chem. 278, 26319-26322. doi: 10. 1074/jbc.C300184200

Werner, T., Liu, G., Kang, D., Ekengren, S., Steiner, H., and Hultmark, D. (2000). A family of peptidoglycan recognition proteins in the fruit fly Drosophila melanogaster. Proc. Natl. Acad. Sci. U.S.A. 97, 13772-13777. doi: 10.1073/pnas. 97.25 .13772 
Wilson, A. C. C., Dunbar, H. E., Davis, G. K., Hunter, W. B., Stern, D. L., and Moran, N. A. (2006). A dual-genome microarray for the pea aphid, Acyrthosiphon pisum, and its obligate bacterial symbiont, Buchnera aphidicola. BMC Genomics 7:50. doi: 10.1186/14712164-7-50

Yan, R., Small, S., Desplan, C., Dearolf, C. R., and Darnell, J. E. (1996). Identification of a Stat gene that functions in Drosophila development. Cell 84, 421-430.

Ye, Y. H., Woolfit, M., Rancès, E., O'Neill, S. L., and McGraw, E. A. (2013). Wolbachia-associated bacterial protection in the mosquito Aedes aegypti. PLoS Negl. Trop. Dis. 7:e2362. doi: 10.1371/journal.pntd.0002 362.5001

Yu, X.-Q., and Kanost, M. R. (2003). Manduca sexta lipopolysaccharide-specific immulectin-2 protects larvae from bacterial infection. Dev. Comp. Immunol. 27, 189-196. doi: 10.1016/S0145-305X(02)00099-X

Zelensky, A. N., and Gready, J. E. (2005). The C-type lectin-like domain superfamily. FEBS J. 272, 6179-6217. doi: 10.1111/j.1742-4658.2005. 05031.x
Zhao, P., Li, J., Wang, Y., and Jiang, H. (2007). Broad-spectrum antimicrobial activity of the reactive compounds generated in vitro by Manduca sexta phenoloxidase. Insect Biochem. Mol. Biol. 37, 952-959. doi: 10.1016/j.ibmb. 2007.05.001

Zhu, Y., Ragan, E. J., and Kanost, M. R. (2010). Leureptin: a soluble, extracellular leucine-rich repeat protein from Manduca sexta that binds lipopolysaccharide. Insect Biochem. Mol. Biol. 40, 713-722. doi: 10.1016/j.ibmb.2010.07.002

Conflict of Interest Statement: The authors declare that the research was conducted in the absence of any commercial or financial relationships that could be construed as a potential conflict of interest.

Copyright $\odot 2016$ Arp, Hunter and Pelz-Stelinski. This is an open-access article distributed under the terms of the Creative Commons Attribution License (CC BY). The use, distribution or reproduction in other forums is permitted, provided the original author(s) or licensor are credited and that the original publication in this journal is cited, in accordance with accepted academic practice. No use, distribution or reproduction is permitted which does not comply with these terms. 